\title{
A REEVALUATION OF THE TAXONOMIC STATUS OF THE RODENT MASILLAMYS TOBIEN, 1954 FROM MESSEL (GERMANY, LATE EARLY TO EARLY MIDDLE EOCENE, 48-47 M.Y.)
}

\author{
MONIQUE VIANEY-LIAUD ${ }^{1, *}$, LAURENT MARIVAUX ${ }^{1}$, THOMAS LEHMANN $^{2}$
}

\begin{abstract}
1 Laboratoire de Paléontologie, Institut des Sciences de l'Évolution de Montpellier (ISE-M, UMR 5554, UM/CNRS/IRD/EPHE), C.C. 064, Université de Montpellier, place Eugène Bataillon, F-34095 Montpellier Cedex 05, France; e-mail: Monique.Vianey-Liaud@UMontpellier.fr. ${ }^{2}$ Senckenberg Research Institute and Natural History Museum Frankfurt, Department Messel Research and Mammalogy, Senckenberganlage 25, 60325 Frankfurt am Main, Germany.

* corresponding author
\end{abstract}

Vianey-Liaud, M., Marivaux, L., Lehmann, T. (2019): A reevaluation of the taxonomic status of the rodent Masillamys ToBiEN, 1954 from Messel (Germany, late early to early middle Eocene, 48-47 m.y.). - Fossil Imprint, 75(3-4): 454-483, Praha. ISSN 2533-4050 (print), ISSN 2533-4069 (on-line).

\begin{abstract}
This paper clarifies the identification of the three species referred by Tobien (1954) to the genus Masillamys from Messel, and more specifically provides a revision of their diagnosis and differential dental features, using an updated terminology. Based on specimens better preserved than the holotype (M. beegeri), it appears that this genus had an infraorbital area more hystricomorphous than sciuromorphous. As the genus shares dental features - like a long oblique postprotocristid or the occurrence of a metalophid I on the lower molars, the relatively well-developed hypocone on the upper molars, as well as hystricomorphy -, notably with Hartenbergeromys and Pantrogna, Masillamys is here included among the basal Theridomorpha.
\end{abstract}

Key words: Masillamys, Rodentia Theridomorpha, Messel, early middle Eocene

Received: April 1, 2019 | Accepted: October 10, 2019| Issued: December 30, 2019

\section{Introduction}

The genus Masillamys, defined by Tobien (1954) for three rodent species (M. beegeri, M. krugi and M. parvus) from Messel, locality dated a little younger than the early Eocene/ middle Eocene boundary, 48-47.5 m.y. (Lenz et al. 2015), was so far considered as a member of a North-American rodent group, the Ischyromyoidea, within the tribe Microparamyini. Ischyromoyids are known to be protrogomorphous rodents, i.e. with a small infraorbital foramen (i.o.f.), dedicated only for the passage of nerves and blood vessels for the toothrow below. However, in Masillamys, the infraorbital region was described as 'sciuromorphous' since Tobien (1954), and this condition was assumed by Hartenberger $(1968,1969)$, then by Escarguel (1999). The sciuromophous condition is defined by a distomesial lengthening of the medial masseter in front of the ramus ascendens of the zygoma. This ascending branch forms a plateau delimited by a muscular scar, which compresses the i.o.f. area. In addition, the lateral masseter attaches at the front to an outgrowth of the maxillary. As a result, the i.o.f. is reduced to a narrow slot in sciuromorphous rodents. It is generally accepted that this specialized condition makes its appearance with the early squirrels, between the late Eocene and the early Oligocene
(Emry and Thorington 1983, Vianey-Liaud 1974, Emry and Korth 2007). It is therefore surprising that, besides allusions to their derived cranial anatomy (Hartenberger 1968: 1817), this earlier occurrence of sciuromorphy represented by Masillamys (late early/early middle Eocene) has not been taken into account and discussed before. The fact that the skulls of the specimens observed by Tobien (1954) were never illustrated, and that since the extraction of their teeth for description, their snout region is damaged, probably explain the misunderstanding of the i.o.f. region.

The three species of Masillamys were originally described by Tobien (1954), but the smaller one, M. parvus, was subsequently transferred to Microparamys (Hartenberger 1968), later to its subgenus Sparnacomys (Hartenberger 1971) and finally to Hartenbergeromys (Escarguel 1999). This last attribution was mainly based on evolutionary trends inferred between Pantrogna russelli and Hartenbergeromys, but without a detailed assessment of their dental features. In fact, Hartenberger (1968) considered that M. parvus differed from $M$. beegeri and $M$. krugi, and was closer to Microparamys, 'for its mesially-shifted buccal cusps on the lower molars (being actually lingual [internal] cusps and not buccal [external] cuspids)'. Also, he suggested for the first 
time that the 'sciuromorphous' species of Masillamys could not be included in the Pseudosciuridae (Theridomorpha) as suggested by Tobien (1954) and others (Schaub 1958, Thaler 1966, Michaux 1968), because basal theridomyids, like Protadelomys, already showed an enlarged i.o.f. (i.e. 'hystricomorphous') as early as the middle Eocene (Egerkingen; Hartenberger 1968, 1969). Later, the same author formally considered Masillamys as belonging to the Ischyromyidae, because its dental pattern is not strongly distinct from that of Pantrogna (Hartenberger 1993: 166), which was until recently included in the Microparamyini (Ischyromyidae). Pantrogna and Hartenbergeromys are now considered as basal Theridomorpha on the bases of their dental features (see Vianey-Liaud and Marivaux 2017; additional work in preparation), and we show that they are hystricomorphous (see below).

Worth mentioning is the footnote by Hartenberger (1990), reporting the presence of an unpublished Masillamys specimen from Messel that bears a large i.o.f., according to R. Lavocat (com. pers. in Hartenberger 1990). In another footnote, Hartenberger (1993) specified that the specimen is SMF-ME 1287 (mistakenly referred as HLMD-Me 1287), which appeared to him to be in fact Microparamys parvus. Escarguel (1999) relayed this information, but added that SMF-ME 1287 was instead a juvenile individual of the genus Masillamys, according to G. Storch and C. Seiffert (com. pers. in Escarguel 1999). Incidentally, a photograph of the specimen SMF-ME 1287 was published without further description by Koenigswald et al. (1992). Unaware of this picture, and still under the impression that adult Masillamys individuals show the 'sciuromorphous' condition, Escarguel (1999) hypothesized that, like the Bathyergidae (see Maier and Schrenk 1987), the i.o.f. get reduced during ontogeny in Masillamys. More recently, Ruf and Lehmann (2018) gave an overview of the Messel rodents in which, based on new specimens (e.g. adult SMF-ME 11295), they casted doubt on the alleged 'sciuromorphous' condition, and called for a revised interpretation of the infraorbital structure in Masillamys.

This paper intends to reconsider the infraorbital features of Masillamys on the bases of unstudied material found since the 1960s, and to clarify their systematics. Remarkably, these fossils clearly display a large i.o.f. (i.e. hystricomorphous), through which the medial masseter extends to the snout. Tobien's misinterpretation of the i.o.f. condition is easily explained by the poor state of preservation of the three fossils available in 1954. These specimens are badly crushed and compressed, so that their infraorbital area could not be accurately described, and their dental features remain poorly known. Moreover, we will show that specimen SMF-ME 1287 is a juvenile of $M$. beegeri and not of M. parvus, and further that the transfer of the species parvus to the genus Hartenbergeromys cannot be supported by dental features.

\section{Dental terminology}

A new evaluation of the dental characters appeared to be necessary, using an accurate terminology to allow comparisons based on discrete features, not on global shapes. We used the terminology proposed by Vianey-Liaud and Marivaux (2017: fig. 4) with some modifications, in order to follow the possible homologies (Text-fig. 1). We will describe separately the different elements of the dental features. Pecularly, on the lower teeth, for the metalophid, we noted the position of the insertion of its buccal part (buccal metalophulid: it is median to the protoconid, at its apex $=$ metalophulid I; or at a buccolingual postprotocristid $=$ metalophulid II), as well as the different paths for the attachments of the lingual metalophulid(s). We detailed the components of the 'buccal wall' (Escarguel 1999), between the protoconid and the hypoconid, distinguishing a postprotocristid and the anterior arm of the hypoconid from the ectolophid + mesoconid. The ectolophid is generally very short and lower than the mesoconid it bears. On various European Eocene species, we have identified pre- and postmesoconid spurs swellings or ridges. We used entolophid for the ridge connecting the entoconid to the ectolophid, rather than the classical hypolophid, because this transverse lophid rises from the entoconid, and does not join the hypoconid cuspid. We have observed a 'true' hypolophid on Ailuravus, reduced to its buccal part, rising from the hypoconid. On upper teeth, we paid attention to the attachment of the lingual protoloph with respect to the protocone and its anterior arm (preprotocrista). The term 'lingual cingulum' (Escarguel 1999) is not as precise as necessary to analyse upper tooth features: we distinguished the lingual cusps (protocone and hypocone) from their arms (pre- and post-protocristae, and pre- and post-hypocristae, respectively) and from the endoloph. Its 'antérolophe 2' is the free extremity of the preprotocrista. The 'crête descendant du protocône dans le trigone' is named here the protocrista. Finally, we also paid attention to the different components of the low ectocingulum: paraectocingulum developed buccal to the paracone, mesoectocingulum from part to part of the mesostyle, metaectocingulum buccal to the metacone.

For both lower and upper teeth, we noted a constant position of some extra-ridges/wrinkles. Finally, we did not use in our terminology the term 'notches' introduced by Escarguel (1999: 116), i.e. the transverse valleys between the main alignments of cusps, leading wear. The analyses of wear patterns and inferences on diets are beyond the scope of this paper.

Some features were described under various names: here we used anterostyle for the small tubercle ending the anteroloph lingually (instead of protostyle), because it is an extension of the anteroloph, not of the protocone. It is the same for the posterostyle (not hypostyle, as it is not closely related to the hypocone).

\section{Systematic palaeontology}

A large phylogenetic analysis of late Ypresian to early Bartonian European rodent species will be undertaken in order to highlight the root of the early Theridomorpha and its content (Vianey-Liaud and Marivaux, work in progress). Based on detailed morphological observations of type populations of several Eocene species of theridomorphs and of European 'ischyromyoids', ailuravids and glirids, it will include the different species of Masillamys. However, according to our new evaluation of cranial and 


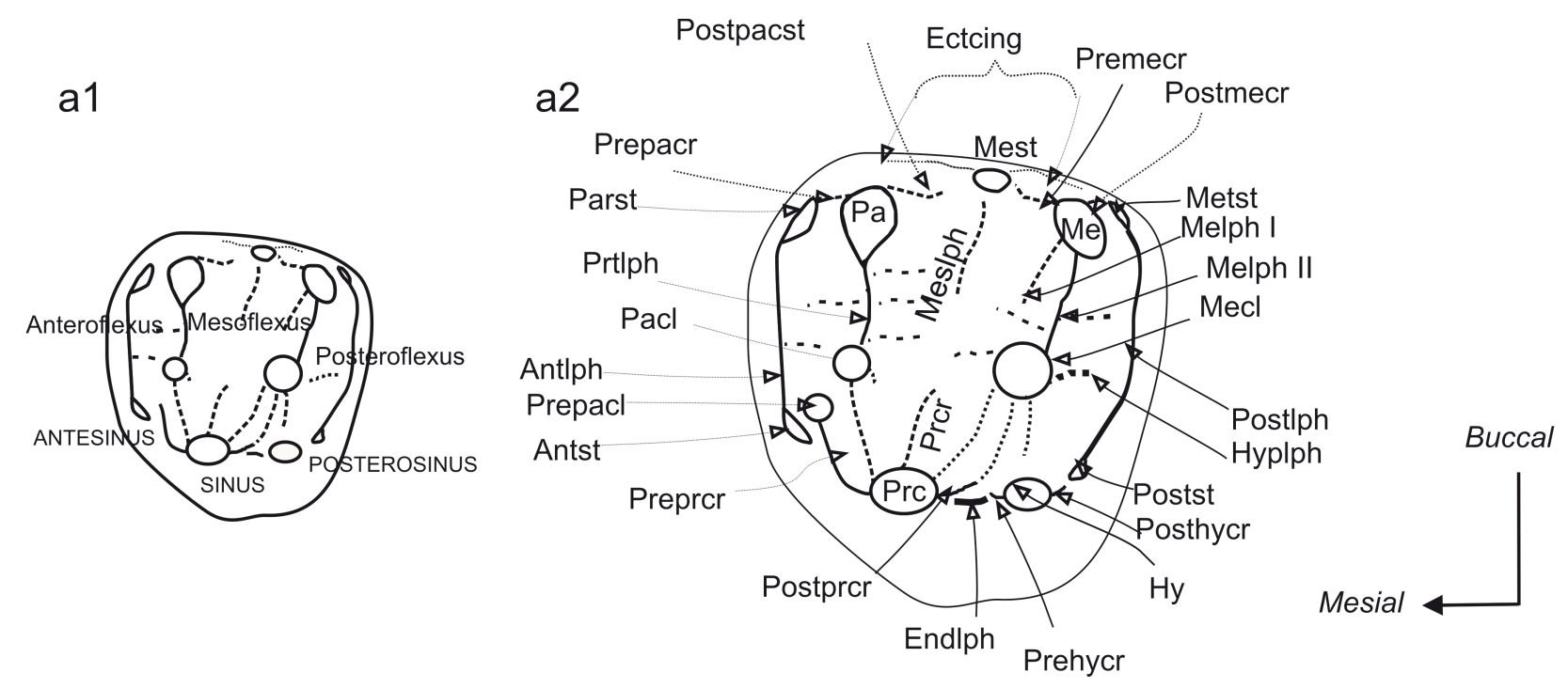

Three positions of the lingual metaloph

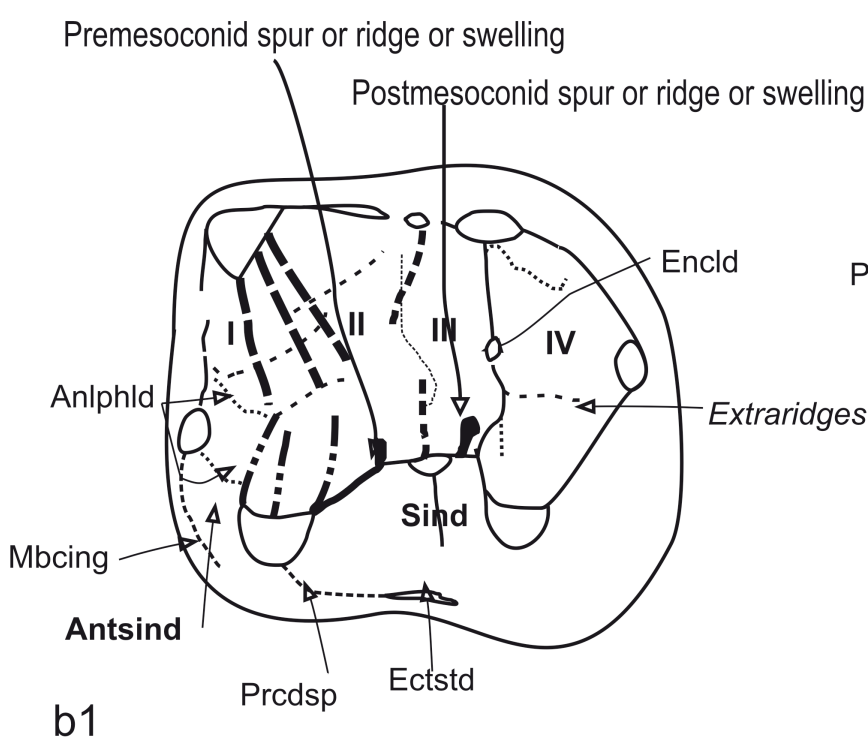

Two positions of the anterolophulid..............

I, II, III, IV = synclinids, flexids

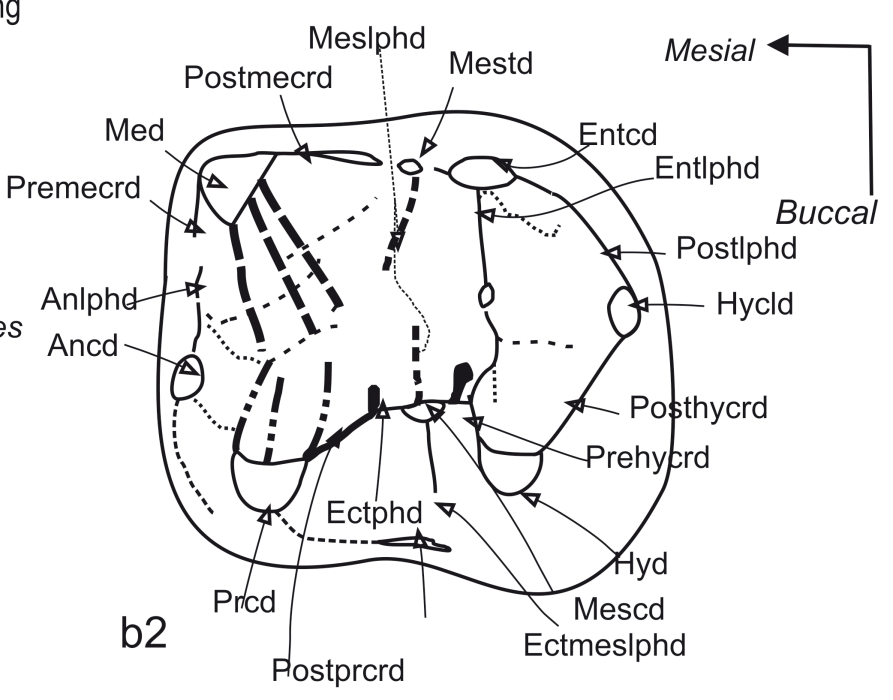

Three positions of the buccal metalophulid: - - Three positions of the lingual metalophulid: _ - -

Text-fig. 1. Dental terminology (modified, after Vianey-Liaud and Marivaux 2019). a) upper molar; a1 - names of flexi on upper molar; a2 - names of cusps and ridges on upper molar. Anlph = anteroloph, Anst $=$ anterostyle, Ectcing $=\mathbf{e c t o c i n g u l u m , ~ E n d l p h ~}=$ endoloph, $\mathrm{Hy}=$ hypocone, $\mathrm{Hyplph}=$ hypolophule, $\mathrm{Me}=$ metacone, $\mathrm{Mecl}=$ metaconule, Melph I = lingual metalophule I, Melph II = lingual metalophule II, Mest = mesostyle, Meslph = mesoloph, Metst = metastyle, Pa $=$ paracone, Pacl $=$ paraconule, Parst $=$ parastyle, Postmecr $=$ postmetacrista, Postpacst $=$ postparacrista, Postst $=$ posterostyle, Postlph $=$ posteroloph, Posthycr $=$ posthypocrista, Prc = protocone, Prcr = protocrista, Prehycr = prehypocrista, Premecr = premetacrista, Prepacl = preparaconule, Preprcr $=$ preprotocrista, Prlph $=$ protoloph. b) lower molar; b1 - names of flexi and some ridges and conules on lower molar; b2 - cusps and ridges on lower molar. Ancd = anteroconid, Anlphd = anterolophid, Anlphld = anterolophulid, Antsnd = antesinusid, Ectmeslphd = ectomesolophid, Ectlphd = ectolophid, Ectsd = ectostylid, Entcd = entoconid, Encld = entoconulid, Enlphd = entolophid (lingual entolophulid + buccal entolophulid), Hyd = hypoconid, Hycld = hypoconulid, Mbcing = mesiobuccal cingulid, Med = metaconid, Mescd $=$ mesoconid, Meslphd $=$ mesolophid $($ lingual mesolophulid + buccal mesolophulid $)$, Mestd $=$ mesostylid, Prcd = protoconid, Prcdsp = protoconid spur, Prehycrd = prehypocristid, Premecrd = premetacristid, Posthycrd = posthypocristid, Postlphd $=$ posterolophid, Postmerd $=$ postmetacristid, Postpred $=$ postprotocristid, Sind $=$ sinusid.

dental features, we consider here that the three species of Masillamys (M. mattaueri, M. beegeri and M. krugi) are closely related and may form a clade within the basalmostsampled theridomorphs (Text-fig. 2). We therefore considered parvus as a species included within the genus Masillamys as initially proposed by Tobien (1954), even if there are some similarities with Hartenbergeromys but also with Pantrogna such as the strong oblique postprotocristid aligned with the ectolophid plus mesoconid on lower molars. However, the main tubercles are more bulged, and, on upper molars, the hypocone is stronger relative to the protocone with a strong endoloph. Masillamys parvus would be the 


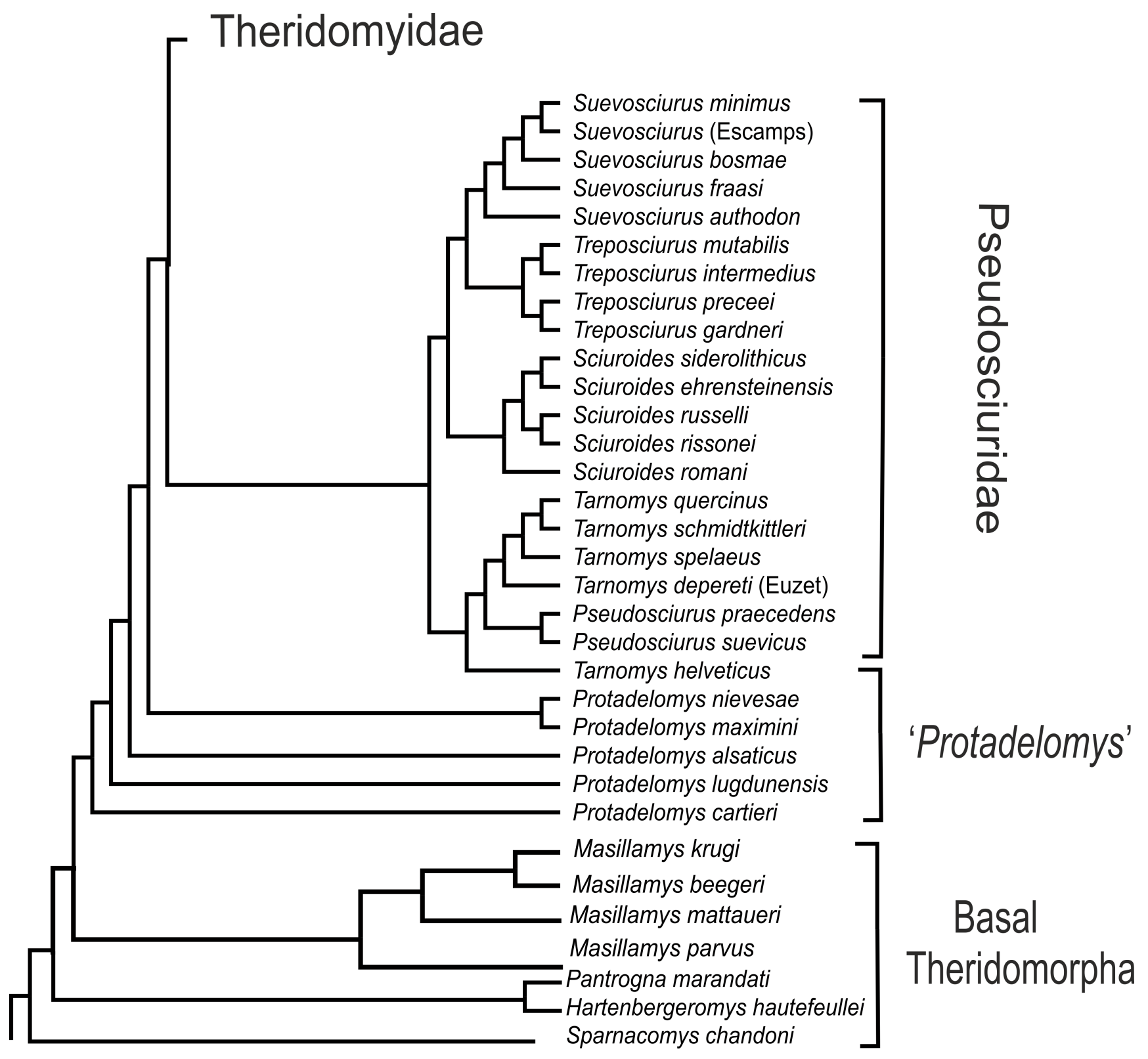

Text-fig. 2. Species of Masillamys considered on the phylogenetic tree of theridomorphs (Vianey-Liaud and Marivaux 2017: fig. 7), within the basal Theridomorpha, before the polyphyletic genus Protadelomys. Position inferred from their dental features (see text).

most basal species of Masillamys, and Hartenbergeromys and Pantrogna their sister group. These two genera display an enlarged i.o.f. (Text-fig. 3), and form a basal theridomorph clade (Vianey-Liaud and Marivaux 2017: fig. 7). Therefore, the genus Masillamys is included within the basal Theridomorpha.

\section{Basal Theridomorpha LAVocat, 1955}

Features of the basal Theridomorpha. Skull with i.o.f. moderately to strongly enlarged. Teeth with moderate unilateral hypsodonty. Enamel of the outskirts of the crowns often rough, sometimes wrinkled on the lingual flank of upper teeth and buccal flank of lower teeth; at least on molars, extra-ridges and wrinkles developed along the main lophs (lophids), descending - converging to the bottom of the syncline(id)s; DP3 (and ? P3) present and peg-like (unicuspate, with a weak lingual cingulum); upper P4 shorter than M1. Upper teeth with hypocone present but more or less smaller and lower than the protocone (more reduced on P4 and even more on M3). On upper molars, paraconule and metaconule still present, variably developed; protoloph and metaloph discontinuous. Lower teeth with metaconid still higher than the other cuspids, with metalophulid I more or less complete, and with mesiobuccal to distolingual oblique postprotocristid, sloping from the protoconid to the short ectolophid; entolophid variably present, incomplete or complete.

\section{Genus Masillamys ToBıEN, 1954}

Ty p e species. Masillamys beegeri ToBien, 1954.

Species included. M. beegeri Tobien, 1954, M. krugi ToBien, 1954, M. mattaueri (HARTENBERGER, 1975) and M. parvus TOBIEN, 1954.

Orig inal diagn o s is.Dental formulaP3-P4-M1-3/ $\mathrm{p} 4-\mathrm{m} 1-3$, sciuromorph rodent from the Pseudosciuridae 


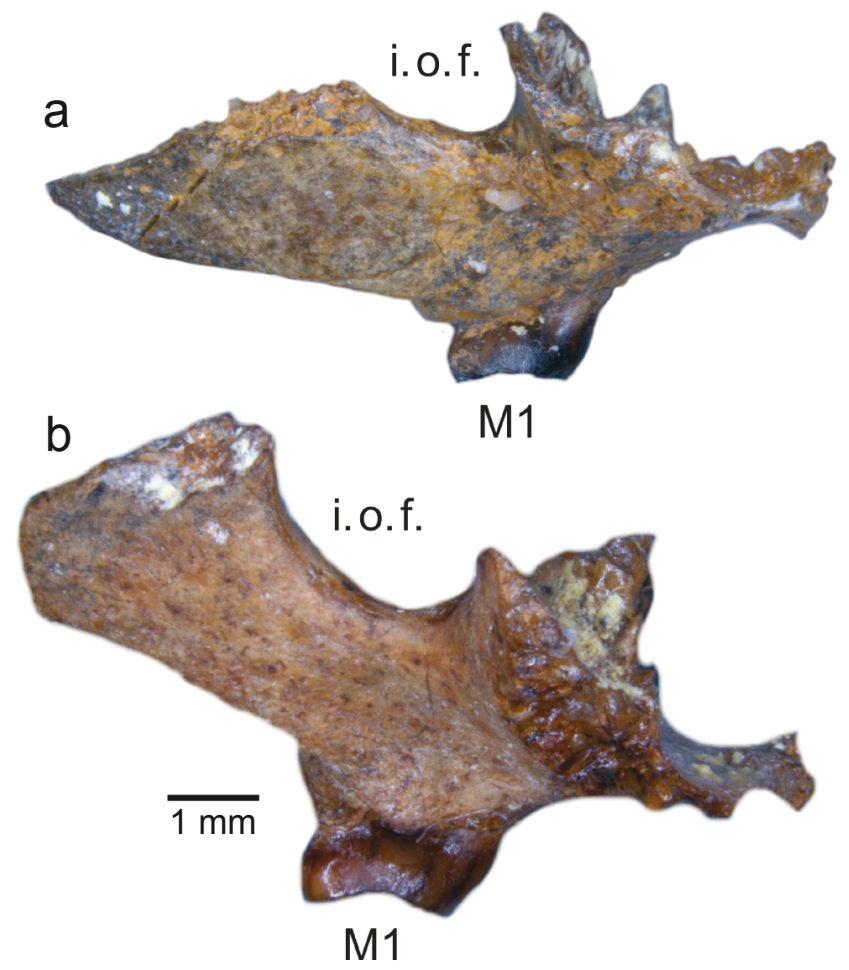

Text-fig. 3. Front views of hemi-maxillaries from Prémontré (Paris Basin, MP 10), showing the large infraorbitary foramen of a) SLP29PR-1312, stored in the Montpellier University collections (ISE-M), Hartenbergeromys hautefeuillei; b) SLP29PR-960, Pantrogna marandati. Scale bar $1 \mathrm{~mm}$.

family; hypocone present on upper molars; metaconule aligned between metacone and protocone. Mesostyle, crestlike and elongated present, aligned between the paracone and the metacone. Lower p4 shorter than molars with only one mesial cuspid. Molars without individualized 'paraconid' (= anteroconid), merged in the anteroloph; metalophid wholly or only partially present, whereas the entolophid is always present, albeit more or less pronounced; ectolophid developed, with weak mesoconid; hypoconulid weak to absent; occlusal surface of the upper and lower cheek teeth with relatively coarse wrinkles and furrow. On the dentary, front edge of the masseter pit reaching the mesial end of $\mathrm{m} 2$. (Tobien 1954, translation adapted from German).

Previous emended diagnosis. Thaler (1966, translation from French): 'Pseudosciuridae with imperfectly quadrangular upper molars: protocone and hypocone close together, sinus incompletely developed, metaconule aligned between protocone and metacone.'

Escarguel (1999, translation from French): 'Large sized Microparamyini; P3 present and occlusal surface of enamel strongly wrinkled; low-crowned jugal teeth. Anterior edge of the masseteric fossa reaches the mesial edge of $\mathrm{m} 2$. Mesial part of P4 reduced. M1-2 with massive conules and mesostyle; the hypocone tends to be as large as the protocone; metaconule weakly or not linked at all to the protocone, to the hypocone or to the lingual margin (= endoloph?); metacone significantly more lingual than the paracone. Strong metaconule, on M3. p4 stocky; ectolophid and posterior cingulid well-developed. On $\mathrm{ml}-2$, the postprotocristid stops shortly before reaching the mesoconid; it is prolonged in a well-developed but rarely complete hypolophid [= entolophid]; massive posterior cingulid, with a well-marked interruption between hypoconulid and entoconid. $\mathrm{m} 3$ with trigonid basin widely open distally, and a usually well-developed hypoconulid.'

New emended diagnosis. Basal Theridomorpha. Enamel rough to strongly wrinkled on the outskirts of the crown; wrinkles and granules numerous in the mesoflexus. Preparacrista absent on M1-M2; parastyle moderate on $\mathrm{M} 2$; ectocingulum variably present on M1-M2; one to two mesolophs on M1-M2; one to two mesostyles on M3; metalophule II variably connected to the posteroloph; posthypocrista variably present on $\mathrm{M} 1-\mathrm{M} 2$; paracone strongly higher than the protocone on M3. On m2, trigonid only slightly higher than the talonid; buccal mesolophid distinct from a postmesoconid ridge; more than three mesiodistal extra-ridges along the distal slope of the trigonid on molars; ectomesolophid present on dp4 and p4; buccal entolophid connected/directed to the postmesoconid ridge; buccal anterolophulid absent on molars; entoconulid variably present.

Differential diagnosis. The genus Masillamys differs from:

- Pantrogna and Hartenbergeromys in its less reduced p4, its metaconid less high than the other cuspids, the hypocone larger compared to the protocone, although remaining smaller.

- Protadelomys in the occurrence of an ectolophid bearing a mesoconid (cf. original diagnosis of Stehlin and Schaub 1951), the lingual metalophule (or metaconule lingual connection) lower and more mesial (to the postprotocrista or the endoloph, exceptionnally to the hypocone).

\section{Masillamys beegeri ToBIEn, 1954 Text-fig. 5, Pls 1, 2}

Holotype. A poorly preserved skeleton with the extracted left upper and lower toothrows, housed at the Hessisches Landesmuseum Darmstadt (HLMD) under reference number HLMD-Me 1.

Type locality. Messel Fossil Pit (Germany); Transition late Ypresian-early Lutetian, MP 11, 47-48 m.y.

Original diagnosis. Strong and high main cusps on the lower and upper molars. Entoconid especially well developed, so that the lingual opening of the central depression is narrow and $\mathrm{V}$-shaped. Lower molars clearly longer than wide; lingual cusp opposite to buccal. (Tobien 1954: 18-19, translation adapted from German).

Emended diagnosis. Masillamys species larger than $M$. krugi with lower $\mathrm{p} 4$ shorter than $\mathrm{m} 1$ and ectocingulid absent; P4 strongly shorter than M1.

Dimensions of the holotype. Lower teeth (length $\times$ width in $\mathrm{mm}$ ) $-\mathrm{p} 4: 2.23 \times 2 ; \mathrm{m} 1: 2.59 \times 2.41 ; \mathrm{m} 2$ : $2.72 \times 2.45 ; \mathrm{m} 3: 2.87 \times 2.13$; upper teeth (length $\times$ width in $\mathrm{mm})$ - P3: $0.87 \times 0.75 ; \mathrm{P} 4: 1.84 \times 2.41 ; \mathrm{M} 1: 2.33 \times 2.62$; M2: $2.33 \times 2.52 ; \mathrm{M} 3: 2.26 \times 2.13$.

Differential diagnosis. Masillamys beegeri differs from $M$. krugi in its more bulged and higher main 
cusps on upper and lower molars, and with the sinus better marked; lophs and lophids thicker, the bottom of flexids less flat; in the absence of the mesostylid; in the $\mathrm{p} 4$ smaller than $\mathrm{m} 1$; on $\mathrm{p} 4$, the entolophid turns backwards to join the hypoconulid area, whereas it joins the distal ectolophid in M. krugi and M. mattaueri. Differs from M. mattaueri in the hypocone nearly as large as the protocone on M1 and the higher endoloph; the complete thick entolophid on molars.

Referred material. Senckenberg Research Institute and Natural History Museum Frankfurt (SMF). Masillamys beegeri adult: SMF-ME 11295: consisting in Plate A of a complete skeleton, left side; Plate B, skull, right side; and $\mathrm{C}$, teeth extracted from $\mathrm{B}(\mathrm{m} 1, \mathrm{~m} 2$ and $\mathrm{m} 3)$. SMFME 3407: complete skeletton but skull damaged; upper teeth absent; three lower teeth badly exposed, buccally (dp4$\mathrm{m} 2$ ). SMF-ME 11115: skeleton with skull and toothrows compressed and distorted.

Masillamys beegeri juvenile: SMF-ME 1287: complete skeleton, right side (Plate A), with DP3, DP4, M1 and M2 badly exposed; dp4, $\mathrm{m} 1$ and $\mathrm{m} 2$ in buccal views; $\mathrm{M} 3$ and $\mathrm{m} 3$ can be seen on X-ray pictures (Koenigswald et al. 1992: 222, fig. 327). SMF-ME 3567: crushed skull, right side, without upper teeth, only a part of M3; dp4, m1 and $\mathrm{m} 2$ exposed (buccal view).

Hessisches Landesmuseum Darmstadt (HLMD). Masillamys beegeri holotype: HLMD-Me 1: a poorly preserved skeleton of an adult individual with left upper (P3 (DP3?) -P4, M1-M2-M3) and lower (p4-m1-m2-m3) toothrows extracted.

Me a s u r e men t s. The adult skull (SMF-ME 11295) length (from nasal to occipital) is about $5.5 \mathrm{~cm}$, whereas it is about $3.6 \mathrm{~cm}$ for the juvenile (SMF-ME 1287). The length of the adult dentary (incisor excluded) is about $2.5 \mathrm{~cm}$ and $1.8 \mathrm{~cm}$ for the juvenile. The height of the dentary (from top of the coronoid apophysis to the lowest angle) is about $1.95 \mathrm{~cm}$ for the adult and $1.25 \mathrm{~cm}$ for the juvenile. The length of the diastema is $0.45 \mathrm{~cm}$ in the adult SMF-ME 11295. The radius of curvature of the upper incisor in the adult SMF-ME 11295 is $0.8 \mathrm{~cm}$ and of the lower one is $1.6 \mathrm{~cm}$.

The adult specimens SMF-ME 3407 and SMF-ME 11295 have the same humerus (maximum) length of $2.8 \mathrm{~cm}$ and femur (maximum) length of $4 \mathrm{~cm}$. In addition, the radius of SMF-ME 11295 is $2.2 \mathrm{~cm}$ and the tibia is $3.8 \mathrm{~cm}$ long. Their trunk length (measured along the cervical-thoracic-lumbar spine) is about $12.5 \mathrm{~cm}$ for both specimens. In comparison, the juvenile specimen SMF-ME 1287 has a trunk length of about $7.3 \mathrm{~cm}$, a humerus of $2.1 \mathrm{~cm}$, a radius of $1.5 \mathrm{~cm}$, a femur of $2.8 \mathrm{~cm}$, and a tibia of $2.3 \mathrm{~cm}$ in length. The description of postcranial specimens of the Messel rodents is beyond the scope of the present paper and will be exposed in a separate work.

For teeth measurements see Tab. 1 and Text-fig. 4.

D e s c r i p ti o n. Skull. Among the studied specimens, two are well preserved enough to provide accurate character description: one adult (SMF-ME 11295) (P1. 1) and one juvenile (SMF-ME 1287) (P1. 2). A few additional details were observed on the crushed juvenile skull SMF-ME 3567. The individual SMF-ME 11295 is preserved on two plates in the collection: the isolated right side of the skull (11295 B) and the left side of the skull as well as the complete skeleton (11295 A). Also, on the crushed specimen SMF-ME 11115, it is possible to distinguish the presence of a wide i.o.f.

Escarguel (1999) reported the debate around specimen SMF-ME 1287, found in 1982, after Tobien (1954) wrote his paper on the Messel rodents. That specimen was successively considered as a representative of the genus Masillamys, then of the species parvus, either included in the genus Microparamys (Hartenberger 1968) or Microparamys (Sparnacomys) (Hartenberger 1971), and finally as Masillamys beegeri (Koenigswald et al. 1992). Direct examination of the specimen confirmed the later identification as M. beegeri, and the presence of DP3-DP4, as well as unerupted M3/3 suggest further, that the individual was a juvenile.

The snout of SMF-ME 1287 bears an i.o.f. (preserved only on the right side) that is clearly larger than in the 'protrogomorphous' condition, and lacks the plateau on the ramus ascendens of the zygoma, which is typical for 'sciuromorphous' rodents. Like in the adult specimen SMFME 11295, the muscular scars for the medial masseter muscle of SMF-ME 1287 are limited to the ventral and lateral aspects of the zygoma. Therefore, like R. Lavocat, G. Storch and C. Seiffert (op. cit.), we interpret this condition as 'hystricomorphous'.

Even if the bones are more or less fractured, and some have moved and shifted from their original position due to compression and crushing, it is possible to describe accurately the anterior part of the skull, and notably the snout and the infraorbital area of SMF-ME 11295 (Pl. 1, Figs 1,2). The well-preserved nasal extends a little posterior to the i.o.f. level. The snout is relatively short (length of the premaxillary above the incisor $=1.53 \mathrm{~cm}$; length of the premaxillary at the base of the i.o.f. $=0.83 \mathrm{~cm}$; maximum height about $1 \mathrm{~cm}$ ). The i.o.f. is widely open. Its opening reaches the level of the upper surface of the incisor in the adult. In the juvenile, it seems slightly smaller and its opening reaches the base of the incisor alveolus; but the maxillary is broken at its upper part above the i.o.f., and its fragments are overlapping. Moreover, the maxillary base of the border of the i.o.f. is tilted medially, as a result of compressions, which reduces the apparent size of the opening. Despite this, the i.o.f. is large and hystricomorphous in adults as well as in juveniles. The lacrimal is positioned at the mesiodorsal corner of the i.o.f. The suture between the maxillary and the jugal in the arch bordering the i.o.f. laterally is partly exposed on the left side SMF-ME 11295, but it is hardly distinguishable at the base of the zygomatic arch. The jugal occupies the main lateral side of the arch, and the squamosal reaches the middle of its dorsal side. Even fractured, the masseteric plate of the maxillary is distinct mesioventrally.

The lateral profile of the glenoid fossa appears at the distal end of the squamosal, above the mandibular condyle on the right side of SMF-ME 11295. On the left side of SMF-ME 11295 and on the juvenile SMF-ME 1287, the tympanic ring lies behind and against the dentary; it is strong on the latter and as high as the dentary height, whereas it is less high relative to the ramus ascendens on the adult. Therefore, during ontogeny, the bullae does not grow substantially, contra the other parts of the skull and mandible. It is not possible to distinguish the petrosal, this 

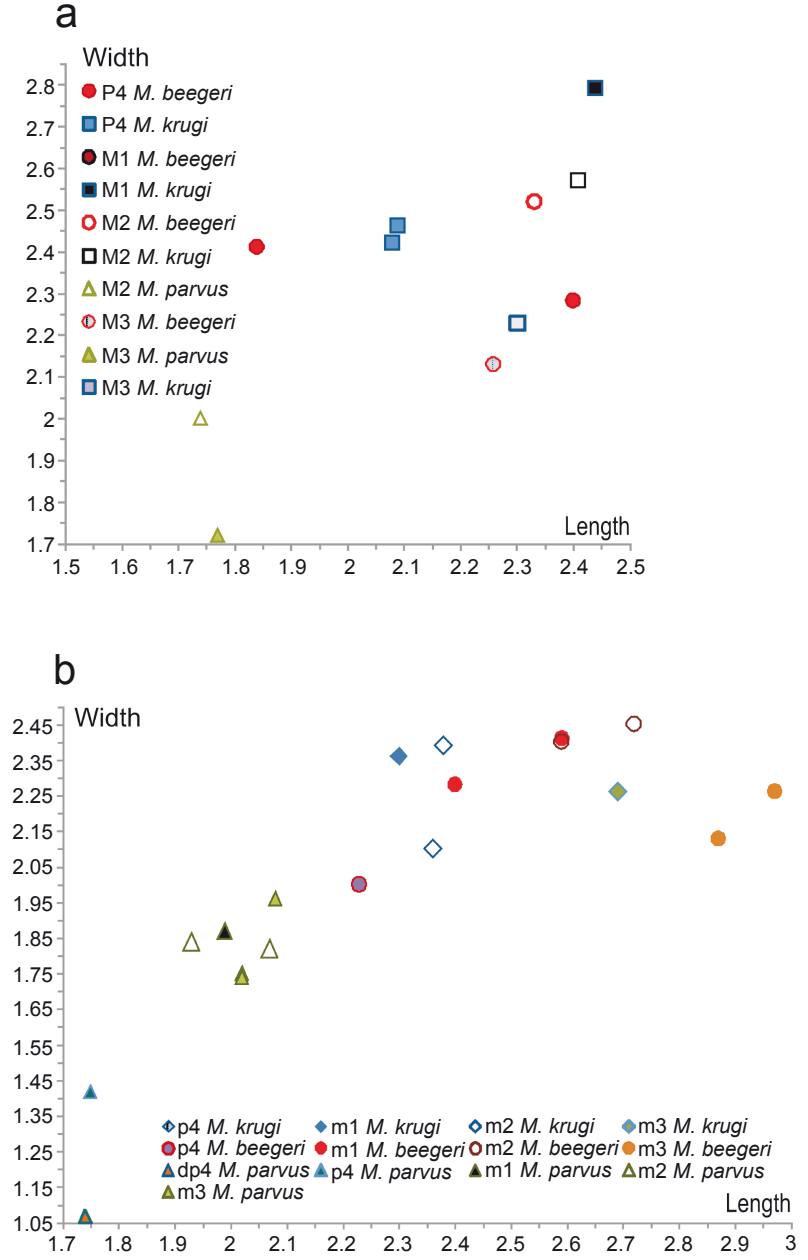

Text-fig. 4. Bivariate graph (length/width) of the teeth of the three species of Masillamys from Messel.

being badly crushed or broken on the right side of SMF-ME 11295. On the juvenile SMF-ME 3567, the right petrosal has been turned inside out and its cerebellar face is exposed, with a wide fossa subarcuata, and a hollow corresponding to the foramina acusticum, but it is still not possible to give more details without a better preparation of the specimen, or a scan of it.

The dorsal row of bones, behind the nasal, shows a flat frontal (as seen on the juvenile SMF-ME 3567); at the middle of the orbit fossa (orbit length about $1.43 \mathrm{~cm}$ ), this frontal is enlarged in a short scalloped postorbital process (seen on all specimens). The temporal fossa is longer than the orbit, but the mosaic of bones involved in this area are mostly obscured, so that the foramina cannot be observed along the lateral walls of the skull. The frontal-parietal suture is visible on the two juvenile specimens. However, the shape of the parietals and their relationships with the squamosal and occipital bones are not clear. On the right side of SMF-ME 11295, a bone seems to be a laterally displaced interparietal or occipital. It is limited distally by a crest, connected to the probable lambdoid crest on each side of which a tear-shaped hollow is marked. It is limited mesially by an incomplete suture.

Dentary. The incisor is long, ending far behind $\mathrm{m} 3$. Even faintly damaged, the diastema appears short (about $0.45 \mathrm{~cm}$ whereas the total length of the jaw, from the mesial margin of the incisor alveolus to the distal end of the angular process, is $2.5 \mathrm{~cm}$ ). On the right side of SMF-ME 11295, the anterior part of the body is shorter than the ramus ascendens (length from the mesial end of the diastema to the mesial corner of the masseteric tubercle $[\mathrm{LmD}] / \mathrm{LmD}+\mathrm{L}$ ramus ascendens $=0.40$ ). The masseteric tubercle reaches mesially the contact between $\mathrm{m} 1$ and $\mathrm{m} 2$. The main foramen mentale is located at mid diastema, well before the p4 mesial root; on the juvenile, it appears closer to the mesial root of dp4. On the adult, one (or two?) additional foramina, smaller and more distally positioned are present.

Teeth. The teeth of the type (HLMD-Me 1) are used here as a reference, and they are then compared to the teeth of other specimens referred to M. beegeri, from the SMF collections.

Upper teeth. See Text-fig. 5b, c.

DP3. It is tiny and has one buccal cusp as seen on the juvenile specimen SMF-ME 1287. On the latter, its apex is strongly worn.

DP4. Present on SMF-ME 1287, its occlusal features are partly hidden. From the lateral view of the skull, it can be observed the two divergent buccal roots (characters of DP4 in most of rodents), which are no more covered by bone. Details on the occlusal face are provided by a scan of the specimen. The anteroloph is long, slightly curved, and ending buccally at the base of the paracone. The anterosyncline is well developed (long and wide). The paracone bears a long sloping postparacrista, ending with a flattened area in contact with the mesostyle base. This is outlined mesiobuccally by a short ectocingulum, and distobuccally by a low ectomesostyle. A short and low mesoloph is present. The protoloph is thick and joins the preprotocrista. The paraconule, smaller than the metaconule, is protruding in the anteroflexus. Pre- and post-protocristae make a wide-open ' $\mathrm{V}$ ' with the protocone apex. The endoloph joins the small hypocone, which connects the long posteroloph, ending before the buccodistal corner of the metacone. The buccal profile of the metacone is stronger than the paracone. There is a premetacrista, shorter than the postparacrista. The thick metaloph lowers before reaching the strong metaconule; the latter is separated from the lingual cusps and lophs. The presence of a dental bud remnant of a probable $\mathrm{P} 4$ is detected on the X-ray picture, between the roots of DP4.

P3. Present on the type specimen, in front of $\mathrm{P} 4$, its unique cusps is pointed; the short lingual cingulum is thin and situated at one third of the height of the crown. It is interpreted as a $\mathrm{P} 3$, because it is unworn, and followed by a P4, contra the worn DP3 on the specimen SMF-ME 1287, which is followed by a DP4. However, as the retention of DP3 is frequent on rodents, we cannot ascertain this.

P4. On the type specimen, this tooth is more trapezoidal than triangular. The anteroloph is short, limited to the middle of the mesial border of the tooth, and the anterosyncline is reduced. The paracone is quite stronger than the metacone (seen also on both sides of SMF-ME 11295), enlarged by its thick postparacrista and thick buccal protolophule. Four low extra-ridges descend from it to the mesosyncline. The protruding paraconule, small and rounded, is adjoined to the middle of the anteroloph, and separated from the buccal metalophule by a shallow notch. It is better connected to the thick preprotocrista. A well-defined extra-ridge descends 
Table 1. List of material and measurements $(\mathrm{L}=$ length, $\mathrm{W}=$ width; in $\mathbf{m m})$ of Masillamys mattaueri from Mas de Gimel (Hérault, France) (MGL) stored in the Instiut des Sciences de l'Evolution, Montpellier University (ISE-M), and Masillamys beegeri, M. krugi and M. parvus from Messel (Hesse, Germany), stored in the Senckenberg Research Institute and Natural History Museum Frankfurt (SMF) and in Hessisches Landesmuseum Darmstadt (HLMD).

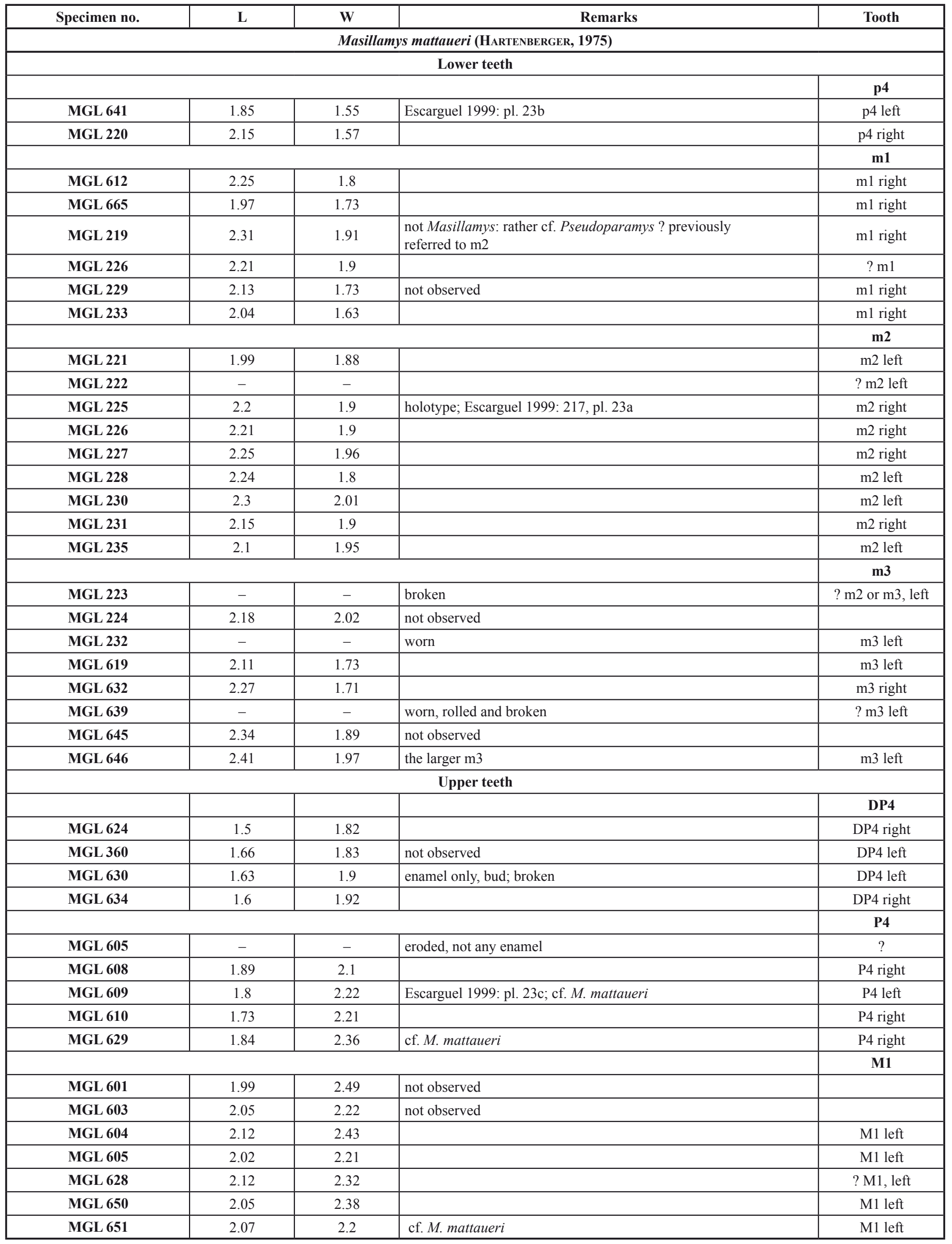


Table 1. continued.

\begin{tabular}{|c|c|c|c|c|}
\hline Specimen no. & $\mathbf{L}$ & $\mathbf{W}$ & Remarks & Tooth \\
\hline & & & & M2 \\
\hline MGL 606 & 2.03 & 2.34 & Escarguel 1999: pl. 23d, as M1-2 & M2 left \\
\hline MGL 615 & 1.92 & 2.17 & cf. M. mattaueri & M2 right \\
\hline MGL 618 & - & - & not measured in Escarguel 1999 & M2 right \\
\hline MGL 622 & 1.9 & 2.2 & & M2 left \\
\hline MGL 623 & 1.89 & 2.2 & & ? M2, right \\
\hline MGL 633 & 2.03 & 2.34 & strongly digested & M2 right \\
\hline & & & & M3 \\
\hline MGL 234 & - & - & worn & M3 left \\
\hline MGL 611 & 2.18 & 2.28 & Escarguel 1999: pl. 23e & M3 left \\
\hline MGL 612 & 1.97 & 2.05 & not observed & \\
\hline MGL 613 & 2.05 & 2.07 & & M3 right \\
\hline MGL 614 & 2.14 & 2.17 & & M3 left \\
\hline MGL 621 & 1.9 & 1.97 & length underestimated in Escarguel 1999 & M3 right \\
\hline MGL 627 & - & 2.03 & previously considered as $\mathrm{P} 4$ & M3 left \\
\hline MGL 631 & 1.95 & 2.05 & very worn & M3 left \\
\hline MGL 638 & 2.09 & 1.96 & very worn & M3 right \\
\hline \multicolumn{5}{|c|}{ Masillamys beegerii TовІEN, 1954} \\
\hline \multirow{4}{*}{$\begin{array}{c}\text { HLMD-Me } 1 \\
\text { Left lower teeth extracted }\end{array}$} & 2.23 & 2 & holotype; Tobien 1954 & p4 left \\
\hline & 2.59 & 2.41 & & $\mathrm{~m} 1$ left \\
\hline & 2.72 & 2.45 & & $\mathrm{~m} 2$ left \\
\hline & 2.87 & 2.13 & & m3 left \\
\hline \multirow{5}{*}{$\begin{array}{c}\text { HLMD-Me 1 } \\
\text { Upper jaw extracted }\end{array}$} & 0.85 & 0.75 & & P3 (DP3) left \\
\hline & 1.84 & 2.41 & & P4 left \\
\hline & 2.33 & 2.62 & & M1 left \\
\hline & 2.33 & 2.52 & & M2left \\
\hline & 2.26 & 2.13 & & M3 left \\
\hline \multirow{3}{*}{$\begin{array}{c}\text { SMF-ME 11295C } \\
\text { Left lower teeth extracted }\end{array}$} & 2.4 & 2.28 & & $\mathrm{~m} 1$ left \\
\hline & 2.59 & 2.4 & & $\mathrm{~m} 2$ left \\
\hline & 2.97 & 2.26 & & m3 left \\
\hline \multicolumn{5}{|c|}{ Masillamys krugi TоBIEN, 1954} \\
\hline \multirow{4}{*}{$\begin{array}{c}\text { HLMD-Me } 910 \\
\text { Left lower teeth extracted }\end{array}$} & 2.23 & 2 & holotype; Tobien 1954 & p4 left \\
\hline & 2.59 & 2.41 & & $\mathrm{~m} 1$ left \\
\hline & 2.72 & 2.45 & & m2 left \\
\hline & 2.87 & 2.13 & & m3 left \\
\hline \multirow{4}{*}{$\begin{array}{c}\text { HLMD-Me } 910 \\
\text { Left upper teeth extracted }\end{array}$} & 1.84 & 2.41 & & P4 left \\
\hline & 2.33 & 2.62 & & M1 left \\
\hline & 2.33 & 2.52 & & M2left \\
\hline & 2.26 & 2.13 & & M3 left \\
\hline \multirow{2}{*}{$\begin{array}{l}\text { HLMD-Me } 910 \\
\text { Right premolars }\end{array}$} & 0.52 & 0.68 & & P3 (DP3?) right \\
\hline & 2.08 & 2.42 & & P4 right \\
\hline \multirow{2}{*}{ HLMD-Me 11015} & \multirow{2}{*}{\multicolumn{2}{|c|}{$\mathrm{L}$ p4 a little longer than $\mathrm{L} \mathrm{m} 1$}} & \multirow{2}{*}{ not measured, but profiles exposed on the pictures (Pl. 3, Fig. 1a) } & $\mathrm{p} 4$ \\
\hline & & & & $\mathrm{m} 1$ \\
\hline \multicolumn{5}{|c|}{ Masillamys parvus TовІеN, 1954} \\
\hline \multirow{4}{*}{$\begin{array}{c}\text { HLMD-Me } \mathbf{6 2 5} \\
\text { Left lower teeth extracted }\end{array}$} & 1.75 & 1.42 & holotype; Tobien 1954 & $\mathrm{p} 4$ left \\
\hline & - & - & & $\mathrm{m} 1$ left: absent \\
\hline & 1.93 & 1.84 & & $\mathrm{~m} 2$ left \\
\hline & 2.02 & 1.75 & & m3 left \\
\hline HLMD-Me 625 & 2.02 & 1.74 & & $\mathrm{~m} 3$ right \\
\hline \multirow{2}{*}{$\begin{array}{l}\text { HLMD-Me } 625 \\
\text { Left upper teeth }\end{array}$} & 1.74 & 2 & & M2left \\
\hline & 1.77 & 1.72 & & M3 left \\
\hline \multirow{4}{*}{$\begin{array}{c}\text { SMF-ME 2099A } \\
\text { Left lower teeth exposed }\end{array}$} & 1.74 & 1.07 & cf. parvus, this paper & dp4 left \\
\hline & 1.99 & 1.87 & & $\mathrm{~m} 1$ left \\
\hline & 2.07 & 1.82 & & $\mathrm{~m} 2$ left \\
\hline & 2.17 & 1.96 & & m3 left \\
\hline
\end{tabular}


from the paraconule to the centre of the mesosyncline. The protocone is swollen, and its thick anterior and posterior arms form a wide ' $\mathrm{V}$ '. A low and short endoloph links the posterior arm to the hypocone. The hypocone is distinct but weakly bulged and fused with the posteroloph, which ends at the base of the metacone. The sinus is narrow and shallow.

The mesiodistally stretched mesostyle is slighly displaced buccally, closer to the end of the postparacrista than to the weak premetacrista. A low ridge is developed at the place of the buccal mesoloph. The bulged metacone is prolonged in a thick buccal metalophule II, which is separated from the strong metaconule by a narrow and relatively deep notch. This metaconule connects to the postprotocrista by a slender ridge. The metaconule bears a mesial outgrowth towards the centre of the mesosyncline. It is of same height as that of the well-developed metalophule I, which runs parallel but lower and narrower than the metalophule II. There are two extraridges on the buccal slope of the protocone, and one thinner on the lingual metalophule, all running towards the basin of the mesosyncline.

M1-M2. These teeth are worn horizontally on the lingual half of the crown, and more vertically on the buccal half (the buccal surfaces of the paracone and metacone), the wear facets being oriented towards the basin.

On the type, M1 differs from M2 in:

- a smaller and closer together protocone and hypocone;

- a less angulated junction preprotocrista-anteroloph;

- a wider buccal opening of the mesosyncline;

- a more mesiodistally stretched mesostyle (or twinned as seen on the buccal profile of the M1 of SMF-ME $11295 \mathrm{~B}$, with two mesolophs (only one on M2));

- a stronger metaconule;

- a more lingual metacone with a shorter posteroloph.

In both cases, there is a relatively deep (about $2 / 5$ of crown height) pinched and narrow sinus.

The parastyle is swollen on both teeth; the low anteroloph joins a bulging (the anterostyle) at the extremity of the preprotocrista. The paracone and metacone have a same size. The buccal protoloph is weakly connected to the paraconule. The latter is bulged and protruding in a ridge weakly separated from the anteroloph. It joins the centre of the protocone. There are two or three low (worn) extra-ridges from the buccal protoloph and the paraconule to the centre of the basin. Like on P4, the postparacrista is thick and strong, whereas the premetacrista is weaker, both being separated from the mesostyle by narrow and shallow notches. The buccal metalophule II is as high and strong as the buccal protoloph, reaching the level of the metaconule to which it is weakly fused. The metaconule is conspicious on M1, weakly divided into two elements. It is less clear on M2, where it appears weaker, but it is much worn. There are several lingual connections of the metaconule: with the postparacrista, with the endoloph or with the hypocone (M1). Low extra-ridges, worn and hardly distinct, are present along the mesial slope of the metaloph and could be the equivalent of the 'metalophule I' of P4. There is a thickening at the end of the posterior arm of the hypocone, better seen on M2 (posterostyle?). The posteroloph is low, ending at the base of the metacone. There are a few extraridges in the anterosyncline and the enamel surface of the crown appears rough, despite some wear.
M3. The protocone and its arms are longer than on M1-2; the parastyle, with a mesiodistal wrinkle, and the anterostyle are present. The protruding paraconule is thin and reduced. The protoloph is connected both to the anterior arm (preprotocrista) and to the apex (protocrista) of the protocone. The mesostyle is followed distally by additional mesostyle and mesoloph. The metacone is low and reduced, displaced distally, making an arcuate cingulum with the shortened posteroloph and posterior arm of the hypocone. The buccal metalophule is low and directed distomesially into the basin. The mesolophs, the metalophule and a ridge from the hypocone-posteroloph area, converge, without connecting, into the mesosyncline to a rounded metaconule. The latter is linked to the postparacrista by a thin ridge (lingual metalophule?). The hypocone is very reduced, but distinct, and a sinus is well present, filled lingually by a small conule (derived from the short endoloph situated above?).

Lower teeth. See Text-fig. 5a.

p4. This tooth is markedly shorter than the $\mathrm{m} 1$. The metaconid, mesiomedian, is the highest and strongest cuspid. Two mesiodistal ridges descend from the apex of the metaconid to the centre of the talonid basin, the more buccal being the strongest. A long and high postmetacristid descends to the narrow mesoflexid opening, which separates the postmetacristid extremity from the entoconid. Buccally, there is a cristid symmetrical to the lingual postmetacristid, but lower, and which ends as a low ectocingulid; it is anteriorly thick (instead of the linguobuccal premetacristid?), and becomes thinner at the base of the hypoconid. Parallel to this cristid, but higher and more lingual, a thick cristid occupies the place of the protoconid (protocristid) at the anterior part of the ectolophid. The buccomesial connections of the protocristid and of the ectocingulid to the metaconid are somewhat worn: it is difficult to decide if a buccal and a lingual metalophulid I are present. The thick protocristid is followed by a premesoconid thickening; then the mesoconid bears lingually a short and angled mesolophid. As the tooth is weakly worn, one can see that the mesoconid is well defined from the thinner and lower ectolophid, the mesial and distal parts of the ectolophid being underlined by shallow and short notches. Two buccal ridges descend one from the distal end of the protocristid, the other from the premesoconid area.

The ectolophid connects the anterior arm of the hypoconid, together with a buccal part of the entolophid, bearing a postmesoconid swelling. The protoconid is slighly higher than the entoconid; it is prolonged in a thick posterior arm separated by a narrow and very shallow notch from the strong hypoconulid, higher than the following short posterolophid. A shallow notch separates this posterolophid from a thick and short posterior arm of the entoconid. The lingual entolophid turns posteriorly to join the hypoconulid. A few weak extra-ridges are seen on the mesial flank of the entoconid and on the distal slope of the metaconid, to the talonid basin.

The enamel of the lingual and buccal flanks of the crown is rough.

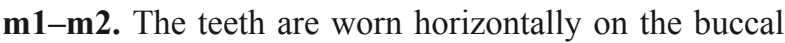
half of the crown, and more vertically on the lingual half (the buccal surfaces of the metaconid and entoconid), the wear facets being oriented towards the basin. The $\mathrm{m} 1$ anterior half is as wide as the posterior half of the $\mathrm{p} 4$. The 'trigonid' of $\mathrm{m} 1$ 
a1
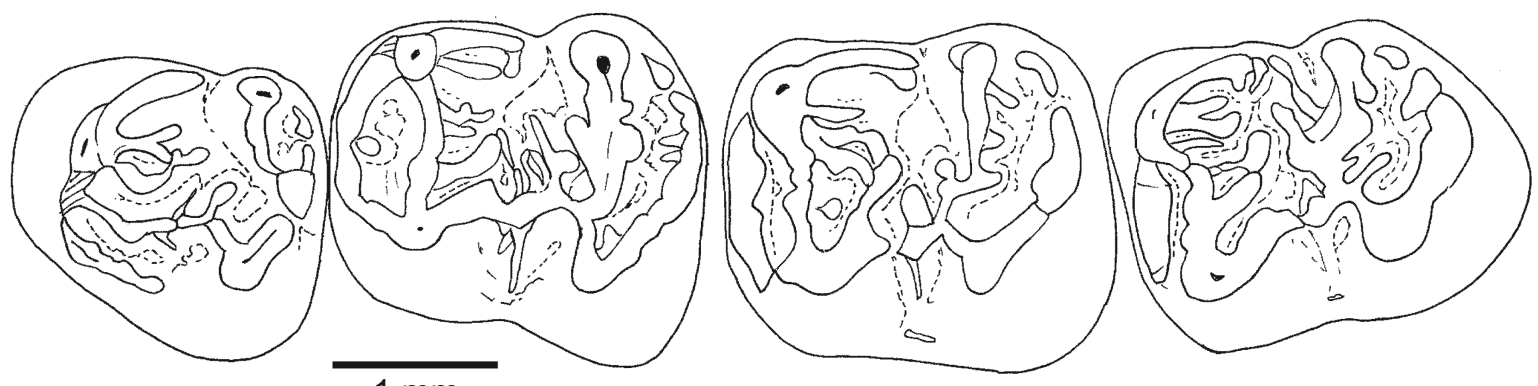

a2

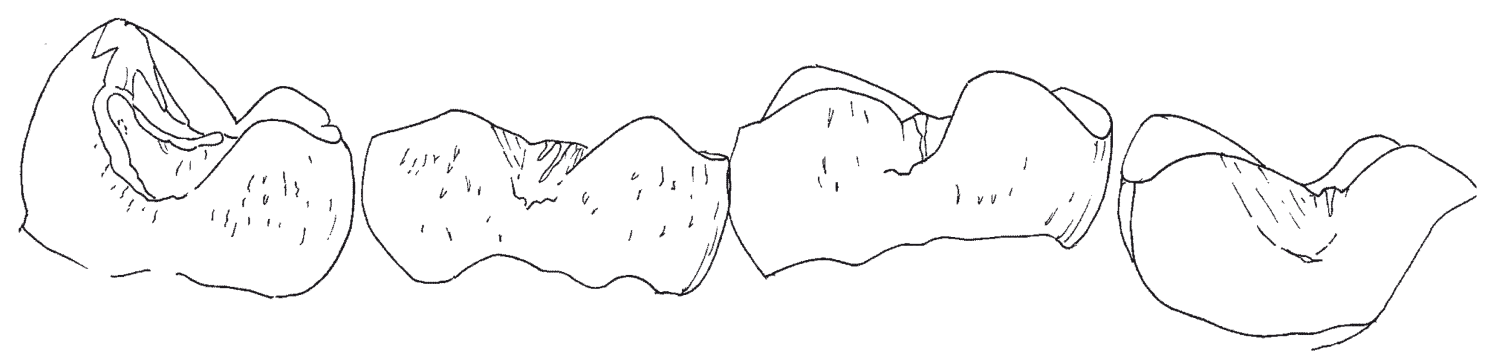

b1

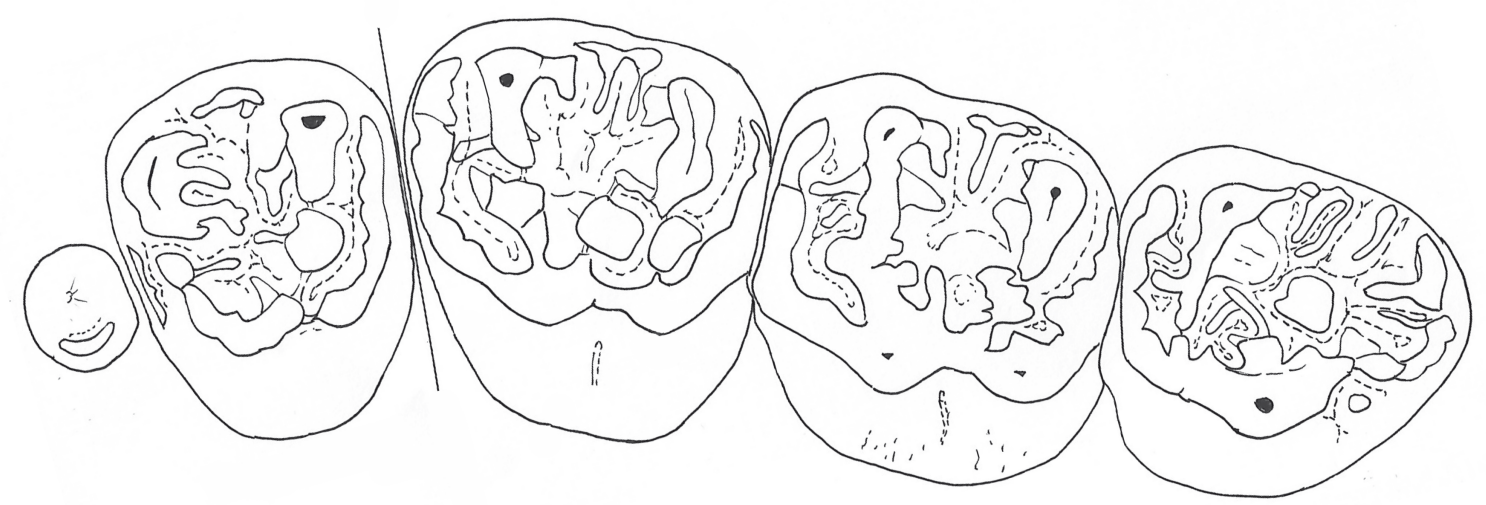

b2

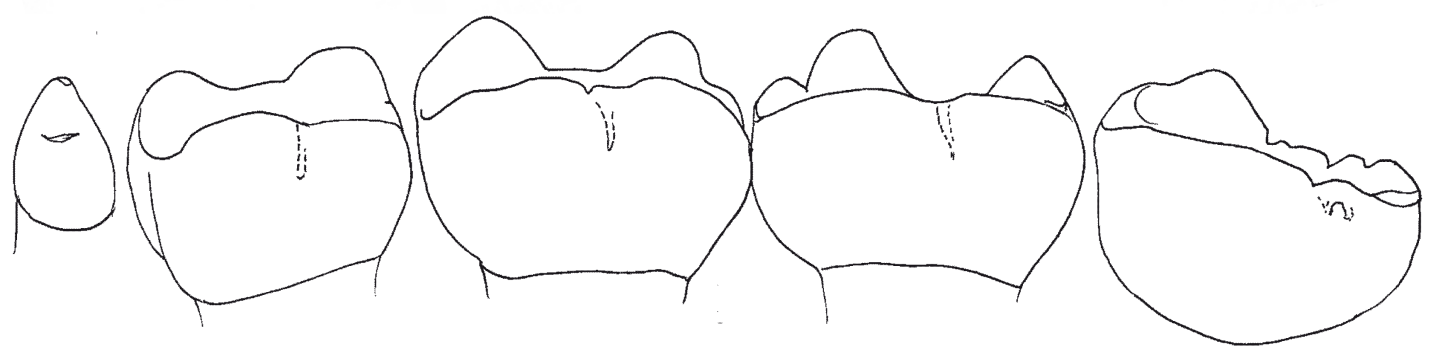

C

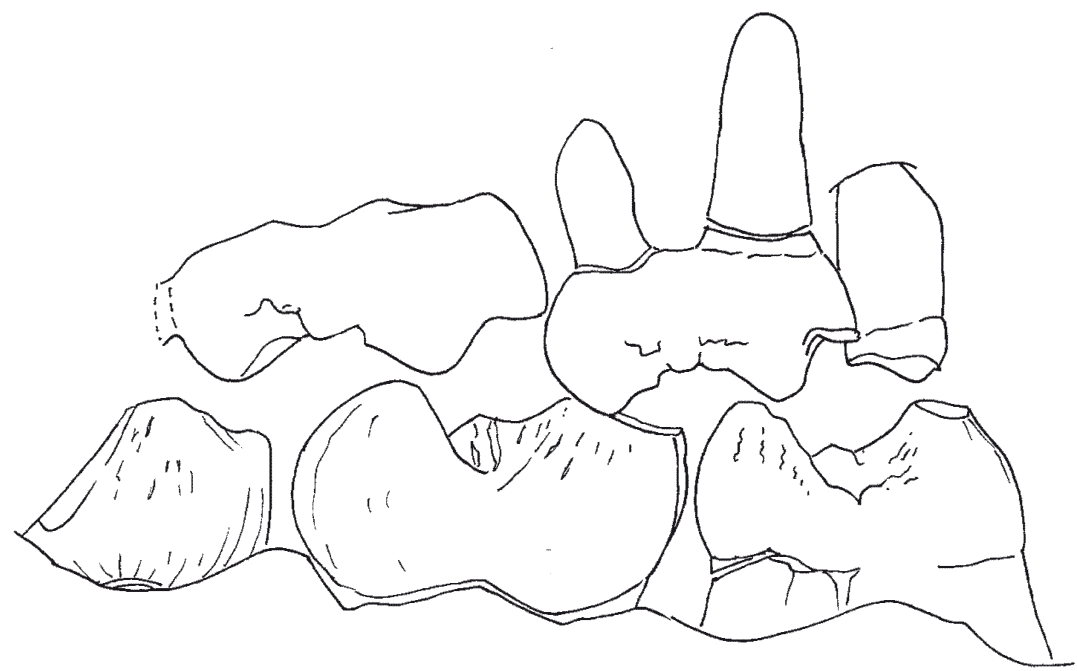

Text-fig. 5. Teeth of Masillamys beegeri TobIEn, from Messel (Hesse, Germany, MP 11). a) HLMD-Me 1, holotype, lower tooth row, p4-m1; a1 - occlusal view, a2 - buccal aspect. b) HLMD-Me 1, holotype, upper tooth row, P3-P4-M1-3; b1 - occlusal view, b2 - lingual aspect. c) SMF-ME 1287A buccal view of teeth, right side of a juvenile, upper M1-DP4-DP3, and lower protoconid of m2-m1-dp4. Scale bar $1 \mathrm{~mm}$. 
is much higher than the basin and posteroflexid, whereas it is only slighly higher on $\mathrm{m} 2$, and of same height on $\mathrm{m} 3$.

The metaconid is the highest cusp; its posterior arm is sharply interrupted at its distal end; on $\mathrm{m} 2$ only, it ends into a short mesolophulid-like linguo-buccal ridge. The postmetacristid is long and high, ending at the lingual opening of the 'mesoflexid', much narrower at its base. The mesostylid is absent. The anteroconid is indistinct from the anterolophid, ending at mid width; it is higher than the bottom of the talonid basin, and higher than the entolophid. It is connected to the anterior arm of the protoconid. The anterosynclinid is narrow and shallow. A linguobuccal premetacristid is present, linked to and aligned with the anterolophid. The buccal metalophulid, developed from the apex of the protoconid, is transverse. It is connected to the lingual metalophulid on $\mathrm{m} 1$ and $\mathrm{m} 2$, making a complete metalophulid I.

The protoconid is slighly distal to the metaconid. The extremity of the long, thick and oblique postprotocristid is swollen and forms a premesoconid spur, prolonged in a long extra-ridge towards the centre of the talonid basin on $\mathrm{m} 2$. The mesial part of the ectolophid and mesoconid are mesiodistally oriented, and the distal part runs more obliquely. The mesoconid is moderately bulged; its buccal flanc bears two $(\mathrm{m} 1)$ or one $(\mathrm{m} 2)$ thin and plunging ectomesolophids. One low mesolophid converges towards the centre of the talonid basin associated with extra-ridges. Another extra-ridge develops from a postmesoconid spur. On the buccal flank, the sinusid reaches the mid-height of the crown. When the enamel is not too heavily worn (as is the case for $\mathrm{m} 1$ ), the sinusid is bounded buccally by one distal ectostylid (m2). The distal ectolophid is short (longer on $\mathrm{m} 2$ than on $\mathrm{m} 1$ ). The prehypocristid is short and thick. The entoconid is the smallest cuspid. The entolophid is low at its buccal half. It is complete, and connects directly to the posthypocristid on $\mathrm{m} 1$, and to the postmesoconid swelling on $\mathrm{m} 2$. The hypoconulid is bulged at the extremity of the posterior arm of the hypoconid. The posterolophid is short, with a short and lower part closing the posterosynclinid. This lophid is related to the posterior arm of the entoconid.

From the lingual metalophulid area to the centre of the basin, there are two short mesiodistal ridges, while another, longer, run from the buccal metalophulid area. These extraridges converge towards the centre of the talonid basin, where they meet another one on $\mathrm{m} 2$, buccolingual, running from the postmesoconid area. There are also short wrinkles from the entolophid and hypoconulid in the posterosynclinid.

$\mathbf{m 3}$. On the single $\mathrm{m} 3$, which is less worn than the $\mathrm{m} 1-2$, the extra-ridges are better exposed in the metalophid and talonid basin area, as well as in the antero- and posterosynclinids. This $\mathrm{m} 3$ differs from the $\mathrm{m} 2$ in its reduced posterolophid and more lingual hypoconulid. A short buccal entolophid is distinct from the connection between the entoconid and the premesoconid ridge.

\section{Masillamys krugi ToBIEN, 1954}

Text-fig. 6, Pl. 3

Holotype. HLMD-Me 910, poorly preserved fragmentary skeleton with complete left upper jaw and lower toothrow, and right P3-P4.
Type locality and distribution. Messel Fossil Pit (Germany). Transition late Ypresian-early Lutetian, MP 11, 47-48 m.y.

Original diagnosis. Similar to $M$. beegeri, but relief of the tooth crowns flat and low. Lower molars wider and shorter than in $M$. begeeri, with main cuspids lower and not protuberant. Entoconid weak. Lingual opening of the central valley of the lower molars wide and open. Enamel wrinkling finer and denser than in M. beegeri. Hypolophid and ectolophid of the lower molars low, but distinct. (Tobien 1954, translation adapted from German).

Emended diagnosis. Teeth close in size to $M$. beegeri, but with different ratios between loci: lower molars wider and shorter than in $M$. begeeri, lower p4 $(2.36 \times 2.1)$ slighly longer than $\mathrm{m} 1(2.3 \times 2.36)$, and $\mathrm{m} 2(2.38 \times 2.39)$ shorter than $\mathrm{m} 3(2.69 \times 2.26)$; main tubercles not strongly protruding; entoconid weak; lingual opening of the central valley at the lower molars wide and open, with a flattened mesostylid, at the distal extremity of the postmetacristid; long oblique postprotocristid nearly aligned with the mesial ectolophid and slender mesoconid.

Enamel wrinkling along the loph(id)s thinner and higher; antero- and posteroloph(id)s, and ectolophid relatively higher; on $\mathrm{P} 4$, nearly complete pericingulum: short anteroloph, protocone, pre- and post-protocristae + endoloph and posteroloph, paracone + postparacrista + mesostyle elements + premetacrista + metacone; relief of the tooth crowns flat, and thinner ridges than in M. beegeri. Tibia longer than the femur (i.e. crural index $>1$ ).

Differential diagnos is. The species Masillamys krugi differs:

- from M. beegeri in overall smaller size and tibia longer than femur; less bulged paracone and metacone, and thinner and higher lophs on upper teeth; on lower molars, presence of mesostylid and mesial ectolophid oblique in the continuity of the postprotocristid, and weaker entoconid; $\mathrm{p} 4$ longer than $\mathrm{m} 1$; on $\mathrm{p} 4$, the entolophid joins the distal ectolophid;

- from M. mattaueri in higher tooth crown; tubercles less bulged; p4 longer relative to $\mathrm{m} 1$; and on $\mathrm{p} 4$, the entolophid complete and higher, joining the distal ectolophid, whereas it is interrupted, lower and joins the prehypocristid or the premesoconid ridge on $M$. mattaueri.

Referred material. Hessisches Landesmuseum Darmstadt (HLMD). HLMD-Me 910, holotype: poorly preserved fragmentary skeleton with complete left upper P3 to $\mathrm{M} 3$ and lower $\mathrm{p} 4$ to $\mathrm{m} 3$, and right P3-P4.

HLMD-Me 11015: Better preserved, although distorted, except for the lower jaws: complete skeleton with an incomplete skull; on the left side, two lower jaws are available, one offering the buccal aspect of $\mathrm{p} 4$ and $\mathrm{m} 1$; on the right side, teeth are not visible.

HLMD-Me 7441: Complete and crushed skeleton with teeth seen from their buccal side (left dp4 (p4 erupting below), $\mathrm{m} 1$ to $\mathrm{m} 3$; upper toothrow complete). The attribution to $M$. krugi is not certain: the erupting $\mathrm{p} 4$ seems as long as $\mathrm{m} 1$, but given that the tooth is still in its crypt, it has not been possible to carry out precise measurement, and to analyse all features. 
M e a s u rements. HLMD-Me 11015 (adult): length of the dentary from the angle to the border of the incisor alveolus $=1.78 \mathrm{~cm}$; height of the dentary $=1.52 \mathrm{~cm}$; length of the diastema $=0.33 \mathrm{~cm}$.

HLMD-Me 7441 (juvenile with p4 erupting): length of dentary $=2.30 \mathrm{~cm}$; height of dentary $=1.72 \mathrm{~cm}$; length of the diastema $=0.44 \mathrm{~cm}$.

The best preserved skeleton (adult HLMD-Me 11015) shows a humerus of $2.1 \mathrm{~cm}$, a radius of $1.6 \mathrm{~cm}$, a femur of $2.6 \mathrm{~cm}$, and a tibia of $3.0 \mathrm{~cm}$ (maximum) length. According to Tobien (1954: 23), the trunk of the holotype (along the cervical-thoracic-lumbar spine) measures $16 \mathrm{~cm}$ long, which would be longer than in M. beegeri. We re-measured the trunk of the holotype and found a length of about $10 \mathrm{~cm}$, whereas the trunk in HLMD-Me 11015 is about $8.5 \mathrm{~cm}$ long.

For teeth measurements see Tab. 1 and Text-fig. 6 .

Description. Skull and dentary. The skulls are particularly damaged but the dentaries are well exposed nonetheless (P1. 3). If the juvenile HLMD-Me 7441 really belongs to $M$. krugi, this individual has a larger dentary than the adult HLMD-Me 11015, both being smaller than the adult of $M$. beegeri, but not much for the juvenile. It is not possible to describe their cranial characters in detail, except that the i.o.f. appears large. The components of the horizontal ramus of the zygomatic arch are seen on the right side of HLMD-Me 11015 (Plate B), the squamosal ending at mid-length, as in $M$. beegeri; the anterior part of the jugal turning along the vertical part of the arch, and the maxillary is well developed at its ventral part.

Teeth. The description is mainly based on the teeth of the type specimen (HLMD-Me 910), as the teeth of the other specimens referred to this species (HLMD-Me 11015 and HLMD-Me 7441) were not extracted and are only partially visible. The comparison of the length of the premolar with that of the first molar allowed us to identify HLMD-Me 11015 (Pl. 3) as M. krugi; as its p4 is not yet erupted, hindering precise measurement, this attribution is less certain for HLMD-Me 7441.

Upper teeth. See Text-fig. 6 a.

P3. Only the left P3 is preserved (Text-fig. 6a1, a4). It is tiny, more reduced compared to $\mathrm{P} 4$ than in $M$. beegeri. The buccal cusp is only slightly higher than the lingual cingulum, which is longer relative to the cusp than in $M$. beegeri, where it is weaker and shorter.

P4. The left P4 is slightly more damaged than the right one, mainly at the level of the anteroloph. This tooth is trapezoidal, with rounded angles. The anteroloph is low, thin and short, but longer than in $M$. beegeri, and does not reach the mesiobuccal border of the tooth. The anterosyncline is reduced as the anteroloph is stuck against the mesial flank. The paracone is faintly stronger than the metacone. The postparacrista is longer but slender than in M. beegeri. Long extra-ridges descend from the paracone, the postparacrista and the buccal part of the protoloph, all towards the mesosyncline. The protoloph is straight and thin in its lingual part, before joining the extremity of the preprotocrista. There is no trace of a paraconule. The protocone is swollen, its thick anterior and posterior arms being nearly aligned mesiodistally. It is difficult to distinguish an endoloph at the distal extremity of the postprotocrista: there is here a swelling corresponding to the hypocone and that continues without interruption into a long posteroloph. There is no development of sinus.

The mesostyle is preceded and followed by equally developed additional mesostyles. All are aligned and slightly displaced buccally, and connected to the postparacrista and to the strong premetacrista, respectively. A buccal mesoloph is well developed from the median mesostyle, converging to the extra-ridges in the mesosyncline. The strong bulged metaconule is connected to the thick metalophule I. An additional ridge lines mesially this metalophule I, from the middle of the metacone. The metaconule joins the postprotocrista through a slender ridge. The metaconule bears a long distal outgrowth towards the posteroloph, and its mesial base displays two thick granules. The metalophule II has two parts: the mesialmost to the metalophule I is short and ends free, whereas the distalmost is directed distally and joins the posteroloph. There are two wrinkles on the buccal slope of the protocone, converging towards the other extra-ridges in the mesosyncline. Two granules make a link between the hypocone and the distal flange of the metaconule.

M1-M2. As the M1 is partly damaged, it is difficult to evaluate the shape of the protocone. M2 differs from M1 mainly in its more lingual metacone, which is weaker than the paracone, and its shorter posteroloph. In both cases, the sinus is shallow, widely open and not pinched. Their parastylar area is not swollen; the anteroloph is thick without anterostyle at the junction with the preprotocrista on M2 (damaged area on M1). The hooklike postparacrista is strong, and makes an arch with the paracone. It is separated from the mesostyle by a narrow notch. The protoloph is continuous from the paracone to the centre of the protocone. From its buccal part, three distomesial extra-ridges runs into the anterosyncline, and also mesiodistal ridges are running to the basin of the mesosyncline. Then the paraconule extends forward, to the anteroloph; two other extra-ridges occur from the paraconule to the centre of the basin. The lingual part of the protoloph bears also extra-ridges directed towards the basin. The mesostyle is slightly stretched mesiodistally and bears two mesolophs; it is followed distally by a short ectocingulum, related to the thin premetacrista, which descends from the metacone. The buccal metaloph is as high and strong as the buccal protoloph on M1, and slightly lower on M2. From it, three (M1) or two (M2) short and thick ridges descend in the mesosyncline, and two (M1) or one (M2) in the posterosyncline. The third mesial extraridge connects to the base of the metaconule (equivalent of metalophule I?). The metaconule is slightly stronger than the paraconule, projecting thick mesial and distal extensions. The lingual part of the metaloph is weak and very low, ending against the postparacrista. Distal to this junction, there is a spur from this arm and another from the hypocone, both ending free. Despite some wear, the enamel surface of the crown is rough, and a network of thin accessory enamel wrinkles is visible.

M3. Even damaged, the size of the protocone and that of its arms are like on M2; the anterostyle is present. The protruding paraconule is thin and reduced; it shows the same extra-ridges seen on the M1-2, but shorter. The tooth is fractured along the protoloph. Nonetheless, it appears that 
a1

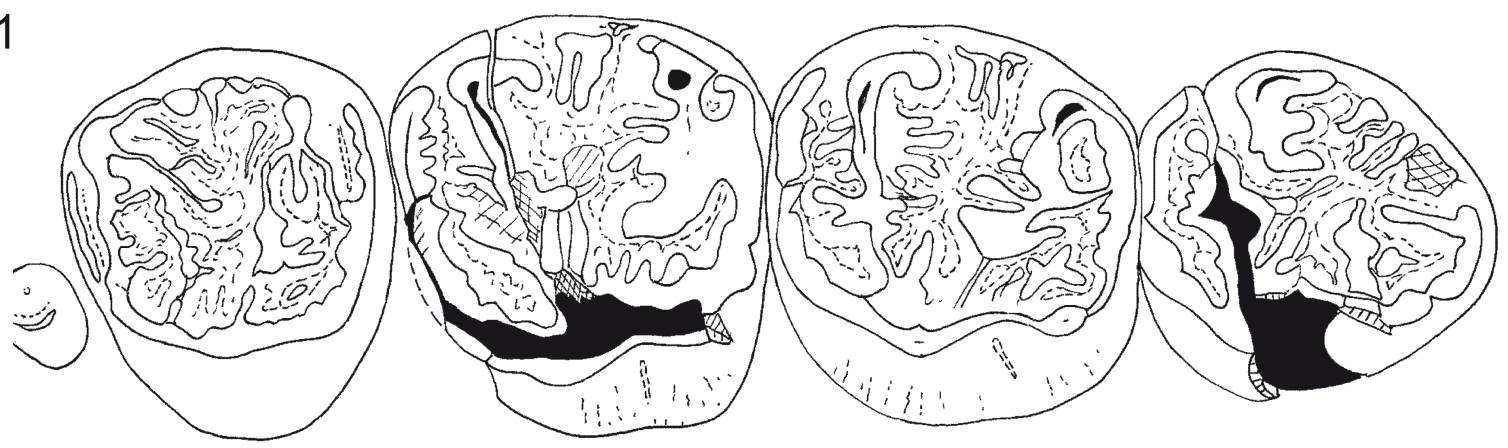

a2

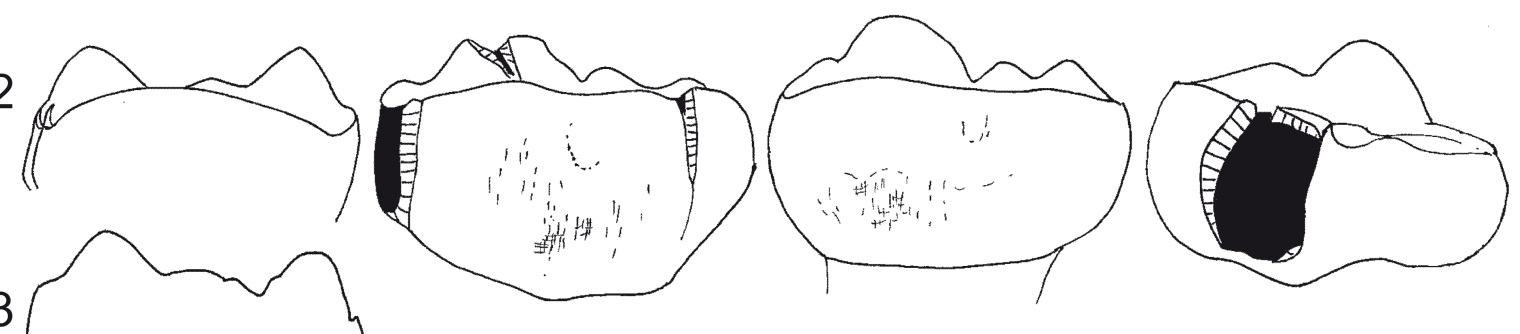

a3

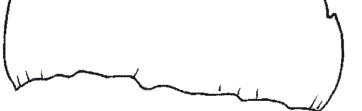

a4

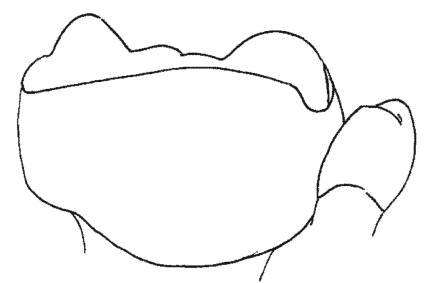

$1 \mathrm{~mm}$

b1

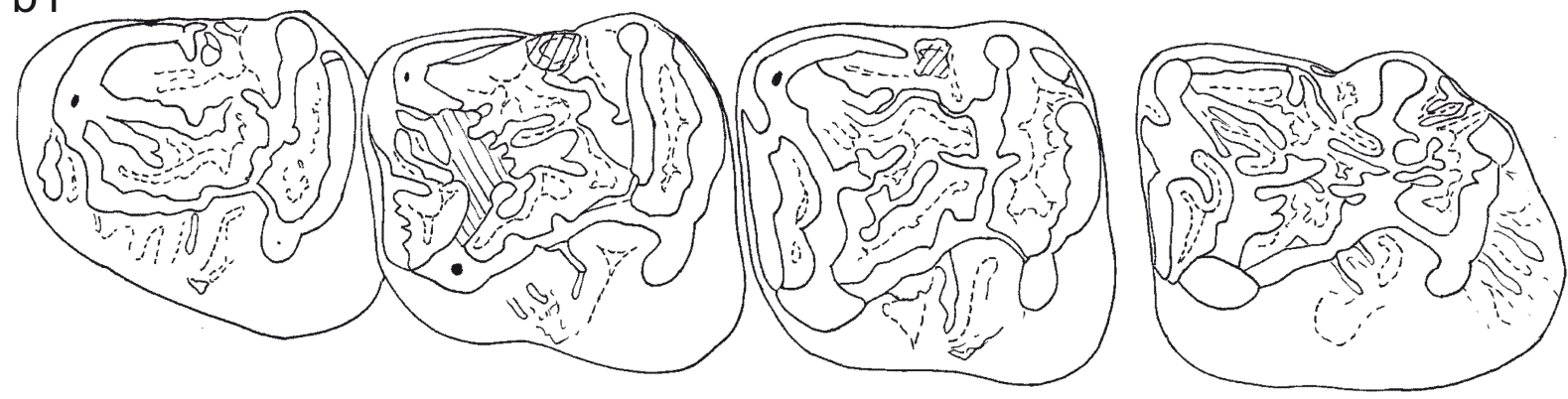

b2

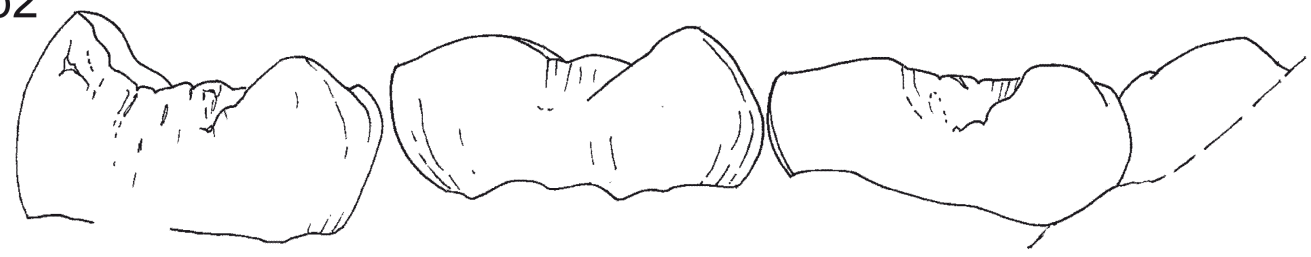

b3

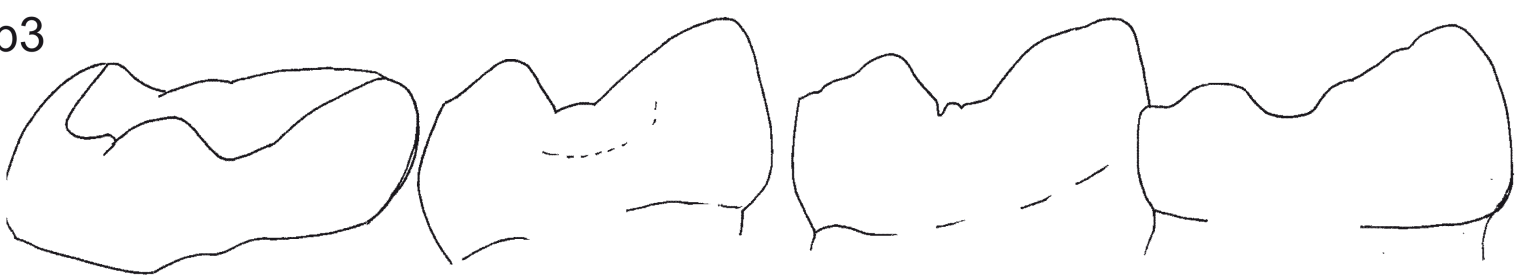

Text-fig. 6. Teeth of Masillamys krugi Tobien, from Messel (Hesse, Germany, MP 11). a) HLMD-Me 910, holotype, upper teeth; a1 - left upper tooth row, P3-P4-M1-3, occlusal view; a2 - id. lingual aspect, a3 - buccal aspect of P4, a4 - right upper P4-P3, lingual aspect. b) HLMD-Me 910, holotype, right lower tooth row, p4-m1-3; b1 - occlusal view, b2 - buccal aspect, b3 - lingual aspect. Scale bar $1 \mathrm{~mm}$. 
the protoloph is continuous and connected to the protocone (even if it is not sure that it is the apex or the anterior arm, due to wear). The mesostyle and mesoloph are followed distally by at least two additional mesostyles and mesolophs. The metacone is not higher than the other elements of the bucco-disto-lingual cingulum. The buccal metalophule (I or II?) is low and directed distomesially into the basin. The hypocone is much reduced, but given that its contact with the protocone is broken, no observation of the endoloph and sinus can be made.

Lower teeth. See Text-fig. $6 \mathrm{~b}$ and Pl. 3.

p4. This tooth is nearly as long as $\mathrm{m} 1$. The metaconid, mesiomedian, is still the highest and strongest cuspid, but it is less prominent than in M. beegeri. Like in M. beegeri, two mesiodistal ridges descend from the apex of the metaconid to the centre of the talonid basin; the lingual-most ridge is the strongest. The postmetacristid is less high and shorter, than in $M$. beegeri, ending with a low and short mesolophulid at the level of a wide lingual opening of the mesosynclinid.

The protoconid is less reduced at the anterior part of the ectolophid than on $M$. beegeri, and is connected to the apex of the metaconid by a 'lingual metalophulid' I. A short linguobuccal premetacristid runs mesially, parallel to this metalophulid. There is no continuous ectocingulid. The thick oblique postprotocristid is followed by a premesoconid thickening; then the mesoconid bears lingually a very short mesolophid. The very short mesial and distal parts of the ectolophid are oblique and aligned obliquely with the weak mesoconid. One buccal ridge descends from the mesial end of the mesoconid (ectomesolophid) towards a buccal spur developed along the buccomesial flank of the hypoconid. The ectolophid connects the prehypocristid, together with the entolophid, which bears a weak postmesoconid swelling. Two short extra-ridges (the longest mesial, the shortest distal) run from the entolophid. Protoconid and entoconid have the same development. The posthypocristid is linked to a regular posterolophid, on which no hypoconulid can be distinguished. Numerous extra-ridges are seen in the mesosynclinid, notably along the main mesiodistal ridge. The buccal slope of the ectolophid area is wrinkled.

$\mathbf{m 1} \mathbf{1} \mathbf{m} \mathbf{2}$. There is less difference in height and strength between the lingual and buccal halves of the wear surface than for M. beegeri, suggesting that horizontal wear is predominant. There is few difference between the height of the 'trigonid' of $\mathrm{ml}$, which is almost at the level of the talonid basin and the posterosynclinid. The enamel outline of the crown is rough and irregularly wrinkled.

Although the metaconid is the highest and strongest cuspid of lower molars, it is lower and blunter, and its posterior arm lower and shorter than in M. beegeri. This creates a wide mesostylar opening for the mesosynclinid before the entoconid. The mesostylid area is worn; if unworn, it would be occupied by a wide mesostylid or a mesostylar flange.

The anteroconid is indistinct on the anterolophid, which ends at mid mesial width. Buccally, it joins the mesial flank of the protoconid, closing the anterosynclinid there; this anterosynclinid is more expanded mesiodistally than in $M$. begeeri. The linguobuccal premetacristid, fused with the mesial flank of the metaconid, is also aligned with the anterolophid. It bears a small anterolophulid, parallel to three (m2) to four (m1) other ridges, the third being the 'lingual metalophulid' I, which joins the extremity of the buccal metalophulid, making an angle on $\mathrm{m} 1$, less pronounced on $\mathrm{m} 2$. This buccal metalophulid, developed from the apex of the protoconid, is postwardly directed on $\mathrm{m} 1$, but less on $\mathrm{m} 2$. Two main extra-ridges run from the metalophid mesiobuccal to distolingual in the talonid basin, where they meet several small extra-ridges from the mesostylid, the ectolophid (mesolophid) or the entolophid areas.

The buccal and lingual main cuspids are more facing each other than on $M$. beegeri. The extremity of the long thick oblique postprotocristid is swollen in a premesoconid bearing only a short lingual spur on $\mathrm{m} 1$. The mesial part of the ectolophid and the mesoconid are obliquely oriented, in the prolongation of the postprotocristid. The distal part of the ectolophid, following the postmesoconid swelling, turns more mesiodistally. The mesoconid is moderately bulged; its buccal flank bears one strong plunging ectomesolophid, which joins a mesiobuccal spur of the hypoconid. The wide sinusid is deep (to mid-height of the crown); its mesial slope bears two wrinkles. The entoconid is the smallest cuspid of lower molars, smaller than the hypoconid. The entolophid joins the distal ectolophid, but is briefly interrupted by a narrow notch separating a short buccal part and a longer lingual one on $\mathrm{m} 1$; the buccal part includes the postmesoconid swelling. Two mesial short extra-ridges are seen along the entolophid on $\mathrm{m} 2$, as well as very short ones into the posterosynclinid, while they are less distinct on the more worn $\mathrm{m} 1$. The prehypocristid is weaker than on $M$. beegeri. The hypoconulid goes from slightly swollen to indistinct. It prolonges in the relatively short posterolophid, related to the posterior arm of the entoconid, thereby closing the posterosynclinid.

m3. On the weakly worn $\mathrm{m} 3$, the numerous extra-ridges are well exposed along the metalophid and in the talonid basin area, as well as in the antero- and posterosynclinids. As for $M$. beegeri, the $\mathrm{m} 3$ differs from the $\mathrm{m} 2$ in its reduced posterolophid and in its more lingually positioned hypoconulid. Here, the entolophid is uninterrupted and bristling with its long mesial and distal extra-ridges. Two or three wrinkles descend distally on the posterior slope of the posthypocristid.

D i s c us s i on. When Tobien (1954) first described Masillamys beegeri and M. krugi, he gave a detailed description of both species (then represented by only one specimen each), and provided arguments in favor of their distinction. Later, Hartenberger (1968, 1993: 166) considered M. krugi as a junior synonym of $M$. beegeri, based on the 'morphological variation observed in the specimens of Vielase [originally identified as Masillamys cf. beegeri by Legendre et al. (1992); but see below]'. Concerning the specimens from Vielase, Hartenberger noted later that they were smaller and somewhat less advanced over the specimens of $M$. beegeri from Messel. In particular, 'the lower p4 is more reduced, and the crenulations in the molars are less developed' (Hartenberger 1993: 166).

Subsequently, Escarguel (1999) assigned the specimens from Vielase to $M$. mattaueri (see below), and suggested that this species (early Eocene, MP 10/11 according to Escarguel 1999) was in the evolutionary lineage leading to M. beegeri from Messel (early-middle Eocene boundary, MP 11). 
Moreover, Escarguel (1999) gave detailed descriptions of the tooth morphology for the different populations he referred to M. mattaueri from France. Like Hartenberger (1968, 1993), he suggested that the differences between $M$. beegeri and $M$. krugi can be found in the different populations of M. mattaueri, and thus that they represent one species only. It is not the case in the type population of M. mattaueri, in which we do not found the thin and high lophs and extra-ridges observed in M. krugi (see description below). Nonetheless, after a careful review of the diagnosis given by Tobien (1954) and the direct comparison of the original and new dental material from Messel, it appears that several discrete and biometrical characters convincingly support the species distinction between M. beegeri and $M$. krugi (see 'Differential diagnosis' above). In particular, we observed that the character ' $\mathrm{p} 4$ longer than $\mathrm{ml}$ ' has been noticed in none of the M. mattaueri populations, making it an autapomorphy of M. krugi. Likewise, the large mesostylid seen on the lower molars of $M$. krugi, but absent in $M$. beegeri, is only present (and if so, quite small) on a few lower m3s of the M. mattaueri population from Mas de Gimel and Naples, and one lower dp4 from Grauves (= Cuis) according to Escarguel (1999).

Finally, considering also its tibia distinctively longer than its femur, we recommend keeping $M$. krugi as a separate species, as originally described by Tobien (1954).

\section{Masillamys parvus (ToBIEN, 1954)}

\section{Text-fig. 7}

Holotype. HLMD-Me 625, poorly preserved skeleton with extracted teeth: left upper M1-M3 and lower p4-m3, right m3;

Type locality. Messel Fossil Pit (Germany). Transition late Ypresian-early Lutetian, MP 11, 47-48 m.y.

Original diagnosis. Definitely smaller than $M$. beegeri and $M$. krugi. On lower molars, the mesial cingulum is separated from the protoconid by a deep incision. The only remain of the metalophid is a posterior arm of the protoconid, whereas a lingual metalophid is missing. The hypolophid [= entolophid] is more sharply defined than in the other two species, proceeding from the entoconid, and joining the ectolophid between the mesoconid and the hypoconid. Entoconid opposite to the hypoconid on the $\mathrm{p} 4$, whereas it is distinctly more mesial on the lower molars. (Tobien 1954: 23-24, translation adapted from German).

E m e $\mathrm{n} d$ e d d i a g n o s i s . Relatively small sized rodent (holotype: $\mathrm{p} 4=1.75 \times 1.42 ; \mathrm{m} 2=1.93 \times 1.84 ; \mathrm{m} 3=2.02$ $\times 1.75$ ), slighly larger than Hartenbergeromys hautefeuillei. On lower molars, lingual main cuspids more mesial than buccal ones; p4 with protruding metaconid, mediomesial, and no protoconid; posterior lobe of $\mathrm{m} 3$ not strongly reduced. On molars, lingual metalophulid I incomplete, buccal metalophulid I ending at midwidth; entolophid complete, attached to the distal ectolophid/prehypocristid junction; ectomesolophid present and hypoconulid reduced. On upper M2 and M3, mesostyle present and positioned only slightly more buccally than the paracone and metacone; hypocone well-developed, with strong pre- and post-hypocristae; shallow sinus present on both teeth.
Differential diagnosis. The species Masillamys parvus differs from:

- M. beegeri and M. krugi in its smaller size; the absence of mesiobuccal cingulid and the reduction of the protocristid on $\mathrm{p} 4$; the absence of lingual metalophulid on lower molars.

- H. hautefeuillei in the absence of mesiobuccal cingulid, the reduction of the protocristid and the metaconid lower relatively to the entoconid on p4; the entolophid more regularly continuous on molars, the less reduced hypocone relative to the protocone on upper molars.

Referred material. Hessisches Landesmuseum Darmstadt (HLMD). Masillamys parvus holotype: HLMDMe 625: a poorly preserved skeleton with teeth extracted: left upper M1-M3 and lower $\mathrm{p} 4-\mathrm{m} 3$, and right $\mathrm{m} 3$.

Senckenberg Research Institute and Natural History Museum Frankfurt (SMF). Masillamys ?parvus juvenile: SMF-ME 2099: a skull badly crushed; a left row of lower teeth exposed in nearly occlusal view (dp4, $\mathrm{m} 1, \mathrm{~m} 2$ and $\mathrm{m} 3$ ).

Measurements. The only known skeleton is that of the holotype (HLMD-Me 625), which is poorly preserved. Almost all its articulations are crushed, distorted or unrecognizable. Nonetheless, its estimated body weight of 55-60 g (Escarguel 1999), and estimated trunk length (measured along the cervical-thoracic-lumbar spine) of less than $80 \mathrm{~mm}$ makes $H$. parvus a smaller animal than $M$. krugi and $M$. beegeri.

For teeth measurements see Tab. 1 and Text-fig. 4.

De s c riptio n. Upper teeth. See Text-fig. 7a, b.

M2-M3. Two fragmentary left teeth have been described and illustrated by Tobien (1954). The left M2 lacks the protocone and its anterior arm plus a part of the anteroloph, and the posterobuccal corner of the crown. The left M3 is less incomplete, lacking only the posterolingual edge of the tooth.

On M2, the buccal part of the anteroloph lacks a parastyle. The anteroloph is regular, thin and low, leaving a well-developed - but narrow - anterosyncline. The paracone and metacone have equal size. The postparacrista and premetacrista are equally developed, both attached to the mesostyle. The latter is low and weakly stretched mesiodistally; it is connected to the mesoloph, which occupies alone the bottom of the small mesosyncline. The buccal part of the protoloph is straight and, after the protruding paraconule, it joins the protocone. From the buccal part of the protoloph, there is one extra-ridge running mesially into the anterosyncline, and three very low extra-ridges descending to the centre of the basin. One linguobuccal extra-ridge starts from the lingual protoloph to the basin. The buccal metalophule II is weak and thin, turning mesially to join the metaconule, which is low and stronger than the paraconule. It is also linked to the posteroloph. Two small low extra-ridges are present along the mesial base of the metaconule. The hypocone is small and the endoloph short; below, the sinus is not well defined. A posterostyle marks the posthypocrista/ posteroloph junction. The posteroloph is higher than the anteroloph, ending at the base of the metacone.

On the weakly worn M3, the parastyle appears slightly swollen at the lingual end of the anteroloph, which is more 

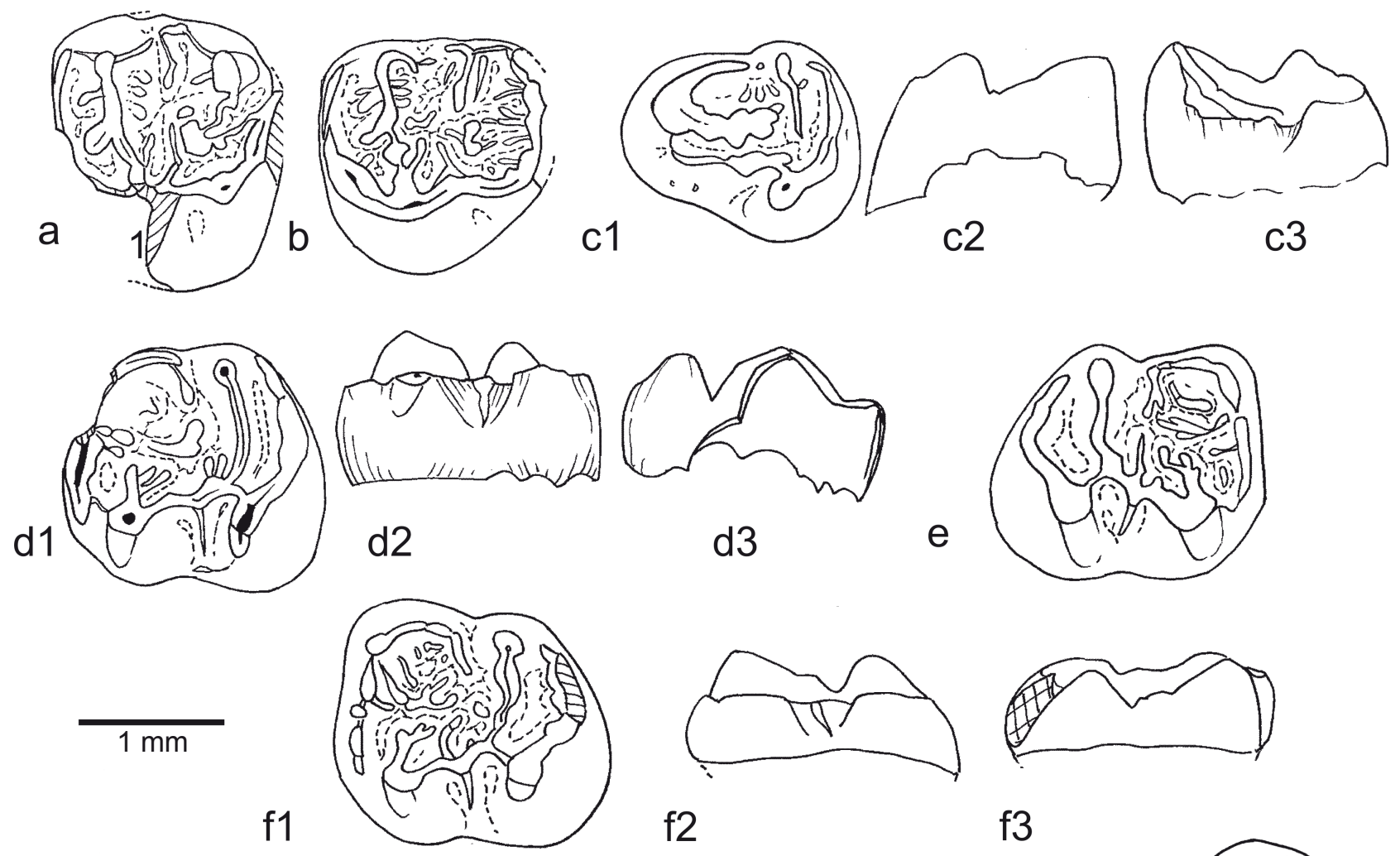

f2

f3

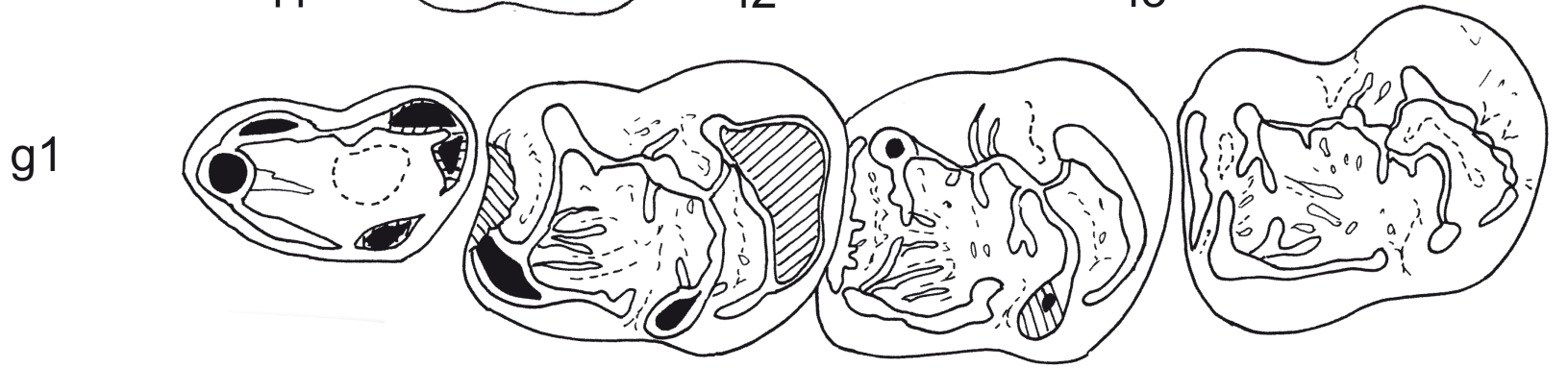

g2

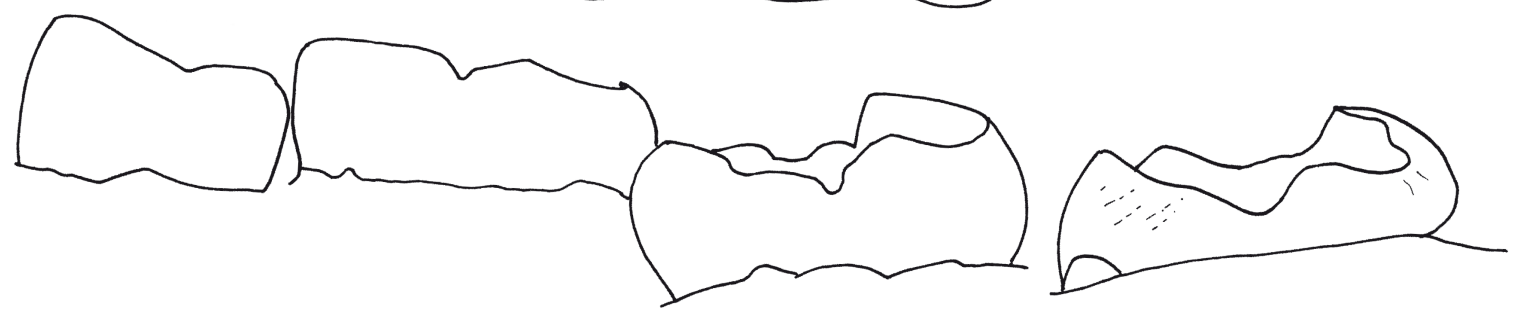

Text-fig. 7. Teeth of Masillamys parvus Tobien, from Messel (Hesse, Germany, MP 11), HLMD-Me 625, holotype. a) left upper M2, protocone damaged, occlusal view. b) left upper M3, occlusal view. c) left lower p4; c1 - occlusal view, c2 - buccal aspect, c3 - lingual aspect. d) left lower m2, metaconid damaged; d1 - occlusal view, d2 - buccal aspect, d3 - lingual aspect. e) right m3, occlusal view. f) left $\mathrm{m3}$; f1 - occlusal view, f2 - buccal aspect, base of crown lacking, f3 - lingual aspect; g) SMF-ME 2099A: right lower tooth row with dp4 to $\mathrm{m} 3, \mathrm{~g} 1$ - occlusal view, g2 - lingual aspect. Scale bar $1 \mathrm{~mm}$.

worn. The mesial end of the preprotocrista is swollen at the place of the anterostyle. The two arms of the protocone make a wide open angle. The buccal half of the protoloph is high and plunging to the level of the low extra-ridges. It bears a stretched and protruding paraconule, and then continues to a swelling before being weakly attached to the thick protocrista. Three extra-ridges are present on the distal slope of the buccal protoloph, parallel to the postparacrista. Another ridge runs from the level of the postparacrista to the basin. The mesostyle is low and stretched mesiodistally; it is prolonged in one short, low and thick mesoloph. The metaconule is present as a low bulged ridge facing the endoloph. The hypocone is reduced; distally, the area between the posthypocrista + the posteroloph + the metacone form a cingulum elevated above the basin. Its posterior edge being broken, precise relationships between these structures cannot be described.

Lower teeth. See Text-fig. 7c-g. The crowns are relatively low and basined, with moderately prominent main cuspids, showing acute lingual ridges.

dp4. SMF-ME 2099: As it is heavily worn, extraridges are not visible. The metaconid is the unique mesial cuspid, from which a faint mesiodistal ridge descends. The protoconid ridge is low and worn. At the opposite, the lingual 
postmetacristid is long and high. The entoconid is isolated from the posterolophid, and the entolophid seems absent.

p4. HLMD-Me 625: This tooth is quite smaller than $\mathrm{m} 1$. The metaconid, mesiomedian, is the highest and strongest cuspid. Its posterior arm descends gently towards the mesosynclinid lingual opening. The tooth is slightly damaged, but it is possible to see one main low mesiodistal ridge descending from the apex of the metaconid to the centre of the talonid basin. The postmetacristid is gently sploping. The protoconid is absent and the protocristid ridge hardly visible. A swelling indicates the presence of a mesoconid. There is a break between a spur at the junction between the ectolophid - anterior arm of the hypoconid and the thin and continuous entolophid. The posthypocristid makes an angle with the long posterolophid, which joins the distal slope of the entoconid. The hypoconulid is not distinct.

m2-m3. HLMD-Me 625: Only one fragmentary $\mathrm{m} 1$, one slightly damaged $\mathrm{m} 2$, and the two $\mathrm{m} 3 \mathrm{~s}$ are known. On the well-preserved surfaces of teeth, the enamel of the crown outline is rough. Like in $M$. krugi, the lingual cuspids are less high than the buccal ones. But there is neither an isolated mesostylid nor a wide lingual opening for the mesosynclinid in front of the entoconid. On $\mathrm{m} 2$, the postmetacristid descends first gently, then more abruptly at the end, from where starts the relatively long mesolophulid (Text-fig. 7d). On $\mathrm{m} 3$, the end of the postmetacristid makes a kind of flat, from which the mesolophulid starts (Text-fig. 7e, f).

The anterolophid is well-preserved only on the $\mathrm{m} 3$ : it is slender, without an anteroconid and it ends lingually at a short mesial and linguobuccal premetacristid. It does not fuse with the protoconid, leaving a narrow buccal opening of the anteroflexid. The anterolophid is higher than the other ridges, which run towards the anteroflexid and mesoflexid. From the metaconid and anterolophid, short and low extraridges descend on the centre of the tooth. Starting from the protoconid, the short buccal metalophulid is the only component of the metalophid being well developed. The thick and oblique postprotocristid bears a premesoconid spur, before the shrinkage of the mesial ectolophid. The mesoconid is bulged (horizontally worn like the protocone and hypocone) and buccally bears the ectomesolophid, as well as lingually a long mesolophid, nearly merged with the mesolophulid. The angled entolophid connects to the distal ectolophid, where it thickens (postmesoconid swelling?). There are two extra-ridges in the anterosynclinid and a few along the lingual slope of the metaconid to the basin and some granules in the posterosynclinid.

m1-m2-m3. SMF-ME 2099 (Text-fig.7g): Like on the holotype, the lingual main cusps are more mesially positioned than the buccal ones, but only slighly more than in $M$. beegeri. The complete anterolophid is transverse, aligned with the plunging mesial premetacristid, without an individualized anteroconid, as on the type specimen; as the teeth are nearly unworn, the buccal end of the anterosynclinid remains open. This feature was argued to differentiate $M$. parvus from $M$. beegeri and $M$. krugi but this opening is not deep. It is found also on the $\mathrm{m} 1$ of $M$. krugi, less worn than the $\mathrm{m} 2$, and on the $\mathrm{m} 3$ of $M$. beegeri, less worn than $\mathrm{m} 2$ and $\mathrm{m} 1$. This feature cannot be used in a differential diagnosis. The lingual metalophulid is stronger than on the type, and weakly joins the buccal metalophulid I on $\mathrm{m} 1$ and $\mathrm{m} 2$. The postmetacristid has the same organization as on the type with a narrow lingual opening of the mesosynclinid, but it ends into a shorter low lingual mesolophulid. Like on the type, the entolophid is complete, attached to the distal ectolophid junction with the prehypocristid. The ectomesolophid is present and the hypoconulid is reduced. The extra-ridges are better marked (but the teeth are less worn). Like for the type, the width of the posterior lobe of the $\mathrm{m} 3$ is only slightly reduced.

\section{Masillamys mattaueri (HARTENBERGER, 1975) Text-figs 10, 11}

Remarks. We revise and redescribe the type population of M. mattaueri, from Mas de Gimel, and Naples (same stratigraphical level) in order to apply an accurate terminology and avoid subjectivity. Owing to Escarguel (1999), the species M. mattaueri is present in the 'ageian' fauna (early Eocene, MP?; Paris Basin), the localities of Saint-Agnan, Grauves, Prémontré (early Eocene, MP 8-9, MP 10; Paris Basin), Mas de Gimel (type population), Naples, Azillanet, Mailhac and Bellevue (early Eocene, MP 10; Languedoc, Southern France) and Vielase (earlymiddle Eocene, MP 10/11; Quercy, France). The M2 referred to this species from Prémontré (Escarguel 1999: pl. $24 \mathrm{~g}$ ) shows a crown relatively flat and the main cusps not as bulged as for M. mattaueri. Moreover, the preprotocrista, protocone, postprotocrista, endoloph and hypocone are aligned on the lingual border of the tooth, and the sinus is absent, features not found in typical $M$. mattaueri. The upper teeth from Mailhac (Aude, France) are too small to be representative of $M$. mattaueri. The material from Southern France will be revised later.

Masillamys cf. mattaueri from Vielase (Quercy). The features used to justify the inclusion of this species within the genus Masillamys are not unique apomorphies, like the bulged cusps and the relatively low crown, the break of the mesial ectolophid or the posterolophid break between the hypoconulid and the entoconid (Escarguel 1999: 224), or the development of a short mesoloph, or of a stretched and protruding paraconule. Most are seen in all the basal Theridomorpha. The absence of connection between the metaconule and the protocone, postprotocrista or hypocone is not general neither in the type population of $M$. mattaueri (3/7 M1) and of M. beegeri and M. krugi (see description above and below), nor in the population from Vielase.

The well-developed hypocone is at same height than the protocone, with high lingual and buccal margins; on m1-3, the postprotocristid is frequently strong towards the talonid basin together with a strong entolophid. The increase of size from $\mathrm{m} 1$ to $\mathrm{m} 3$ is not seen in the type population (Escarguel 1999: 225).

For us, if the species from Viélase belongs undoubtly to Masillamys, there are some differences with M. mattaueri, like the more numerous strong and higher extra-ridges, the size slightly smaller and the increase of size from $\mathrm{m} 1$ to $\mathrm{m} 3$. It is the reason why we consider it as $M$. cf. mattaueri.

The jaw of Decticadapis sciuroides from Basin de Paris ('ageian' fauna). This jaw was referred to $M$. mattaueri (Escarguel 1999: 109, 146, 154, 214, 216, 225, pl. 24i, j). The strong entoconid, the well-defined hypoconulid, the 
absence of any entolophid, the short oblique postprotocristid and the strong mesoconid are rather features characterizing Euromys thaleri (Vianey-Liaud and Marivaux, in prep) than Masillamys.

Referred material. Montpellier University, Institut des Sciences de l'Evolution (ISE-M). From Mas de Gimel locality (MGL).

Holotype. MGL 225 (Hartenberger 1975: pl. 1, fig. 17).

Ty pe 1 o c a lit y. Mas de Gimel (Montpellier, Languedoc, France; early middle Eocene, MP 10).

Other localities. ?Saint Agnan (Paris Basin, MP 8-9), Grauves (Paris Basin, MP 10).

Original diagnosis. Species slighly larger than Microparamys russelli and more evolved. Ectolophid and transverse ridges well-developed on lower teeth. On upper teeth, strong hypocone and weakly marked sinus. (Hartenberger 1975: 784, translation from French).

Previous emended diagnosis. Small sized species of the genus Masillamys larger than Hartenbergeromys hautefeuillei and Pantrogna marandati. P4 and p4 of large size relative to molars. DP4 strongly molarized; hypocone very lingual; anterior part of $\mathrm{P} 4$ reduced; hypocone weak or not distinct from the posterior cingulum. M1-2 with strong hypocone, conules and mesostyle; lingual sinus $[=$ anteroflexus $=$ anterosyncline $]$ transverse weakly marked; posterior cingulum much reduced; metacone clearly more lingual than paracone. M3 with conules developed; lingual sinus and mesostyle marked. Trigonid of dp4 bicuspidate; ectolophid and posterior cingulid developed and continuous. Trigonid of p4 unicuspidate; complete ectolophid, lined by a low central ridge descending from the metaconid to the talonid. On m1-2, anterolophid and metalophid complete and high, closing the talonid basin; posterior arm of the protoconid not reaching the mesoconid; posterior cingulid deeply separated from the hypoconulid and entoconid. Trigonid of $\mathrm{m} 3$ open; posterior arm of the protoconid directed to the entoconid; entoconid isolated, sharp and massive. (Escarguel 1999, translation from French).

New emended diagnosis. Species of Masillamys smaller than $M$. beegeri and $M$. krugi, and larger than M. parvus, with M1 slightly longer than M2. DP4 without ectocingulum. P4 with very low anteroloph; differs from P4 of $M$. krugi and M. beegeri in the paracone slightly stronger than the metacone, the paraconule present and strong; the preprotocrista and postprotocrista aligned obliquely, whereas they are mesiodistally aligned for $M$. krugi, and making an obtuse ' $\mathrm{V}$ ' for $M$. beegeri. Buccal metaloph weakly connected to or separated from the metaconule. On M1, protocone slighly lingual with respect to the hypocone, whereas it is at the same level as the hypocone on the other species of Masillamys. On lower teeth, ectolophid longer than in M. beegeri; lingual and buccal parts of the entolophid rarely joined and lingual part often double; postentocristid absent.

Material and measurements. See Tab. 1 and Text-figs 8, 9 .
Type. $\mathrm{L}=2.20 \mathrm{~mm}$; Wtri $=1.90 \mathrm{~mm}$; Wtal $=1.92 \mathrm{~mm}$; Ltri $=1.07 \mathrm{~mm}$ (Escarguel 1999: pl. 23, figs a, b).

D e s c ription. Upper teeth. See Text-fig. 10.

DP4. Only three DP4 are available. The parastyle is swollen and curved on MGL 624 and 634, less on the bud MGL 630. The three teeth display a swollen anterostyle at the lingual end of the anteroloph. The anteroflexus is relatively wide mesiodistally. The postparacrista and premetacrista are present. There are one or two mesostyles prolonged by two short buccal mesolophs. The protoloph is tranverse buccolingually on the two first and oblique postwardly on MGL 630. This protoloph is weakly connected to the rounded protruding paraconule. This paraconule is stronger on MGL 630 than on the others. It is connected to (MGL 624), directed to (MGL 634) the extremity of the anterior arm of the protocone. On MGL 630, it is weakly attached to the protocone by a low lingual protoloph. The buccal metaloph is transverse buccolingual on MGL 624; it shows two branches on MGL 634: the distal one (metalophule II) is curved to the posteroloph; the mesial one (metalophule I) is weaker and linked to the metaconule. Metalophule I and II are present on MGL 630, but the metalophule II does not reach the posteroloph. The low and weak lingual

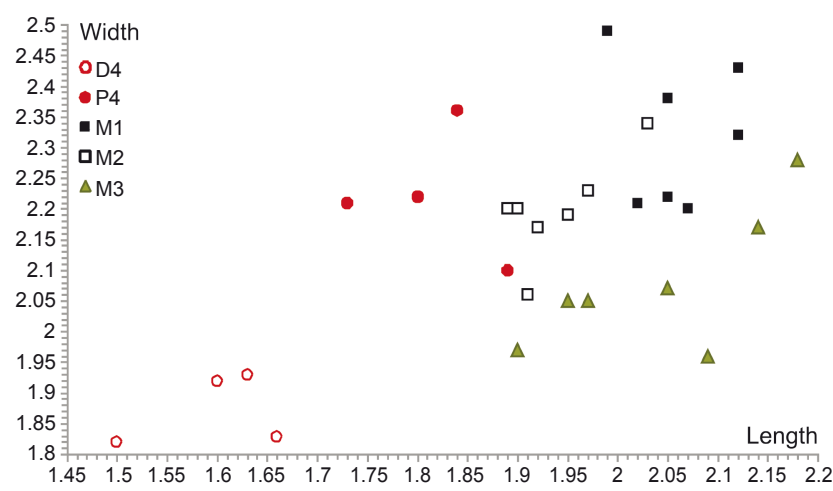

Text-fig. 8. Bivariate graph (length/width) of upper teeth of Masillamys mattaueri (HARTENBERGER) from Mas de Gimel (Hérault, France; MP 10, late early Eocene).

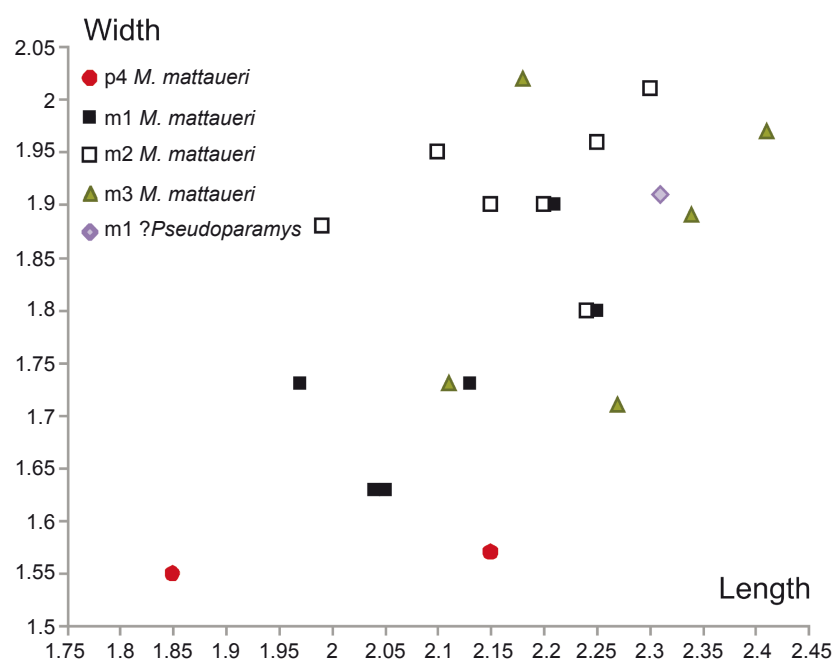

Text-fig. 9. Bivariate graph (length/width) of lower teeth of Masillamys mattaueri (HARTENBERGER) from Mas de Gimel (Hérault, France; MP 10, late early Eocene). 
a1

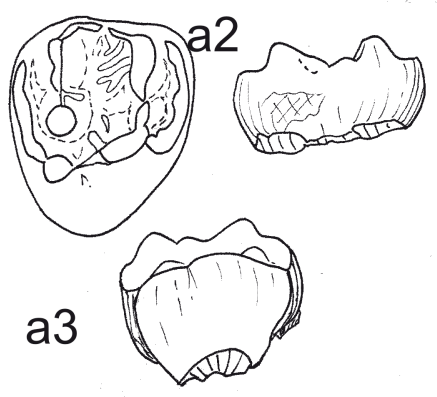

e1
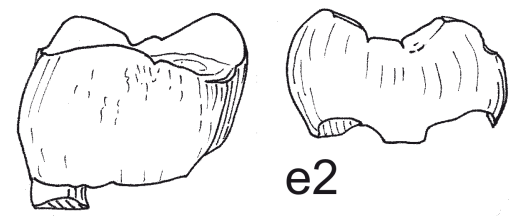

f1

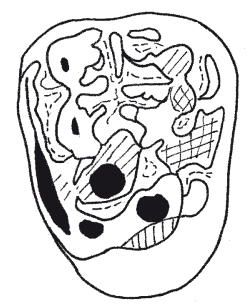

f2

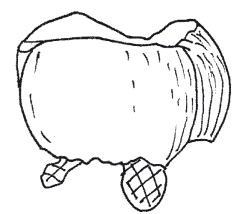

f3

j1

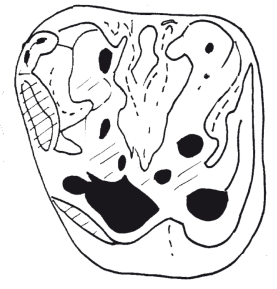

g1
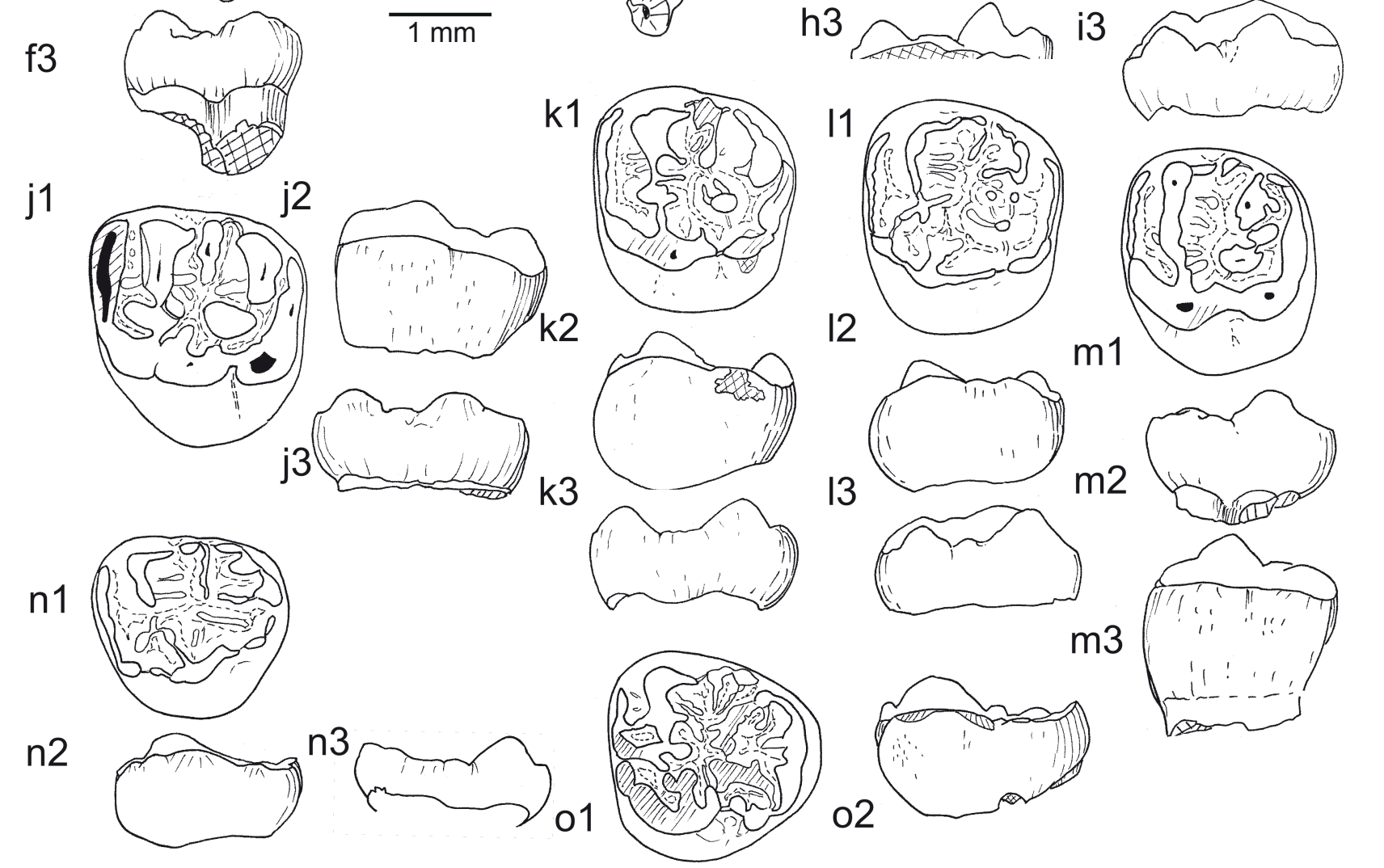

b2

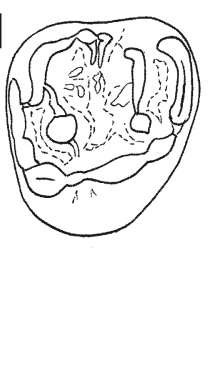

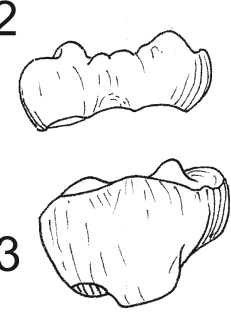

c1

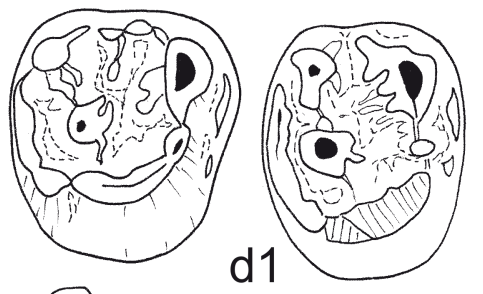

c2

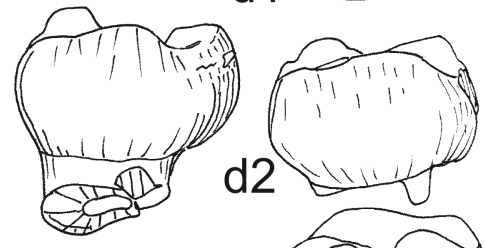

c3

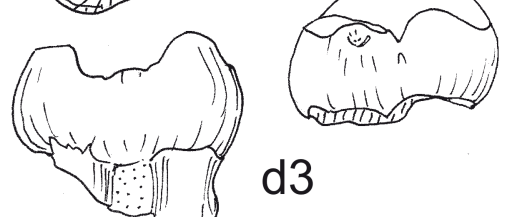

e3

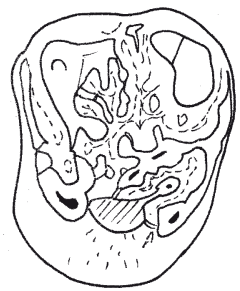

d3

Text-fig. 10. Upper teeth of Masillamys mattaueri (Hartenberger) from Mas de Gimel (Hérault, France; MP 10, late early Eocene). a) MGL 624, right DP4; a1 - occlusal view, a2 - buccal aspect, a3 - lingual aspect. b) MGL 634, right DP4; b1 - occlusal view, b2 - buccal aspect, b3 - lingual aspect. c) MGL 608, right P4; c1 - occlusal view, c2 - lingual aspect, c3 - buccal aspect. d) MGL 610, right P4; d1 - occlusal view, d2 - lingual aspect, d3 - buccal aspect. e) MGL 609, left P4; e1 - lingual aspect, 
metaloph is directed from the base of the metaconule to the beginning of the endoloph or ends at the level of the postprotocrista, thereby leaving the metaconule separated from the protocone along the main part of its elevation. A median arm of the prococone (protocrista) is distinct on MGL 630. The metaconule is stronger than the paraconule; the former is doubled buccally on MGL 630. The hypocone is more lingual than the protocone, and the sinus below the endoloph is narrow and very shallow. The posteroloph is slighly swollen lingually (posteroconule) and relatively short, ending slighly buccally at the level of the metalophule II. The posteroflexus is open buccally. There are a few low and slender extra-ridges within the mesoflexus (one to two from the buccal protoloph, one to two from the mesial metaconule flank).

P4. Only five P4 are available, among them one is damaged. The four others show shape variation associated with morphological differences. MGL 609 (figured in Escarguel 1999) and MGL 629 are trapezoidal, but much narrower mesiodistally than MGL 608; MGL 610 is narrow and oval. It is not possible to decide if these differences reflect distinct species, because there are too less material. Two molars, one M1 (MGL 651) and one M2 (MGL 615) showing a similar pattern of wear of MGL 629, could belong to the same individual.

The anteroloph is always very low; it is adorned to the mesial flank of the teeth on three specimens, and more distinct from this flank on MGL 609. It appears longer on MGL 609 and 629, reaching the mesiobuccal corner of the paracone; it is shorter buccally and weaker on the two others, their lingual end being reduced. On MGL 629, the anteroloph is discontinuous, with a break lingual to the parastylar area, and another lingual to a worn flat enlarged area overflowing (projecting) at the level of the paraconule. The paracone is thicker than the metacone on MGL 605 and 610 , less thick to equal on MGL 609 and 629. The postparacrista, connected to the mesostyle, is more (MGL 609) or less (MGL 629 and 610) displaced lingually, curving then buccally towards the mesostyle; it is rather convex on MGL 608. This postparacrista is lined by a low and short ectocingulum, relatively strong on MGL 629, weak on MGL 609 , reduced to a trace on MGL 610, and absent on MGL 608. The mesostyle is prolonged by a short and thin buccal mesoloph. The buccal protoloph is short and the paraconule distinct, facing or attached to the mesial extremity of the preprotocrista on MGL 610 and 608; it is longer on MGL 609 and 629, on which the paraconule is indistinct, its flat area being worn. On MGL 609, there are four low ridges converging to the basin, two from the postparacrista, being parallel to the mesoloph, one from the distal flank of the paracone, and another from the protoloph. On MGL 629, there is one extra-ridge only from the postparacrista, and it is blunted. Extra-ridges are also present on MGL 610, but shorter; only one thick and bifid is present along the paracone of MGL 608. The premetacrista is short and thick on all specimens. The buccal metaloph is short, thinning at the metaconules area, and its connections vary. On MGL 608, it connects to the buccal extremity of the short posteroloph (metalophule II) and more mesially (metalophule I) to the metaconule. On MGL 610, there is a very short ridge towards the posteroloph, and another ridge, which is longer and slighly stronger towards the large metaconule. On MGL 609 and 629, there is no connection with the long posteroloph, and the thick metalophule II is directed to the metaconule (609), or attached to it (MGL 629). For all specimens, the metaconule is bulged and strong, but it shows singularities on MGL 609 and 629. On MGL 609, the metaconule area is elongated obliquely, its distal extremity reaching the posteroloph, and its mesial one connecting the apex of the protocone. On this specimen, one low extraridge occupies the same position as the 'metalophule I'. There are also one to two extra-ridges extending from the metaconule towards the basin, as found on the other P4; finally, a small extrametaconule is present lingual, and it is weakly linked to the extremity of the postprotocrista. On MGL 629, the metaconule is duplicated, the more buccal is aligned with the metacone-buccal metaloph, and then the larger second is placed in between the first and the protocone: it is much worn, and separated by a notch from the apex of the protocone. Both show thin ridges connected to the lingual part of the posteroloph. The endoloph is not distinct, the hypocone being close to the distal end of the postprotocrista. The hypocone is small, but more (MGL 608 and 629) or less (MGL 609 and 610) distinct. The buccal roots are visible and separated on their upper parts, below the crown for MGL 608, and fused on MGL 609 and 629. They are not preserved on MGL 610.

M1. Seven molars were referred to M1; among them, two are missing in the collection. Our description is therefore based on five M1. All have the protocone and hypocone along the same mesiodistal axis, and buccally, the metacone is placed only slightly lingual to the paracone.

Three (MGL 604, 605 and 650) are similar in shape: they are trapezoidal, with the anteroloph + parastyle projecting mesially, whereas the posteroloph is straight transversely. The parastyle area is elongated and only slighly swollen; it ends lingually by an anterostyle, which connects the extremity of the preprotocrista. The latter is nearly aligned with the postprotocrista, both making a wide angle with the protocone. A very shallow antesinus is well marked on the unworn MGL 604. The shallow and narrow sinus underlines a short endoloph, which is only slightly lower than the main cusps (Text-fig. 10h, i, j). As seen on the unworn tooth, the hypocone is isolated, i.e. it has no well-developed pre- and

e2 - buccal aspect, e3 - occlusal view. f) MGL 629, right P4; f1 - occlusal view, f2 - lingual aspect, f3 - buccal aspect. g) MGL 651, left M1; g1 - occlusal view, g2 - lingual aspect, g3 - buccal aspect. h) MGL 604, left M1; h1 - occlusal view, h2 - lingual aspect, h3 - buccal aspect. i) MGL 628, left M1; i1 - occlusal view, i2 - lingual aspect, i3 - buccal aspect. j) MGL 605, left M1; j1 - occlusal view, j2 - lingual aspect, j3 - buccal aspect. k) MGL 606, left M2; k1 - occlusal view, k2 - lingual aspect, k3 - buccal aspect. l) MGL 602, left M2; 11 - occlusal view, 12 - lingual aspect, 13 - buccal aspect. m) MGL 622, left M2; m1 - occlusal view, m2 - buccal aspect, m3 - lingual aspect. n) MGL 614, left M3; n1 - occlusal view, n2 - lingual aspect, n3- buccal aspect. o) MGL 611, left M3; o1 - occlusal view, 02 - lingual aspect. Scale bar $1 \mathrm{~mm}$. 
post-hypocristae. The short posteroloph is swollen lingually in a small posteroconule. On the other teeth, which are worn, these structures are connected. The anteroflexus is wide, compared to the narrower posteroflexus. The paracone is prolonged lingually by a transverse protoloph, which becomes thin and curves to the protruding paraconule. It bears a plunging postprotocrista, the buccal end of which is concave and separated from the mesostyle by a slot. There is a weak extra-ridge descending from the buccal protoloph to the anteroflexus, parallel to the paraconule; it is better visible on the two worn teeth. Distally, there are one (MGL 650) to two extra-ridges descending to the centre of the mesoflexus. The lingual protoloph is linked to the summit of the protocone (MGL 604) or to the preprotocrista (the two others). The mesostyle is unique; it is isolated or underlined by a small ectocingulum (MGL 605 and 650); it is slighly buccal to the paracone-metacone. It prolonges lingually in a single or double (MGL 650) mesoloph. The short premetacrista + metacone + buccal metaloph make an arch. At its lingual end, there is, distally, a thin and low connection with the metaconule; mesially, a thicker and longer distomesial extraridge descends in the basin. The metaconule is bulged, much stronger than the paraconule. It can bear one more centripetal extra-ridge. A very weak ridge (lingual metaloph) connects the metaconule to the postprotocrista. The surrounding crown enamel is rough. There are rare short extra-ridges in the mesoflexus, or undulations along the inner borders of the anteroloph and posteroloph on MGL 650.

MGL 628 is less trapezoidal, but as the parastyle is long and swollen, and the paracone and metacone on the same mesiodistal line, it is clearly a M1. It is not worn, and the extra-ridges appear clear and more numerous - as well in the mesoflexus as on the mesial flank of the protoloph or the distal flank of the metaloph and metaconule -, than on the three other M1 (MGL 604, 605 and 650). Therefore, there is a well-defined metalophule I, and a junction of the metalophule II with the posteroloph. There are two successive metaconules; the buccalmost is the weaker, stretched in a distal ridge, the stronger is the lingualmost, which bears two distal and two mesial extra-ridges. One can see a short posthypocrista. The mesostyle is double, and the mesoloph relatively long, as it is fused to low granules aligned into the mesoflexus. The other features of this tooth are similar to those described above for the other teeth.

MGL 651 has the same pattern of wear as that of the MGL 629 P4, and could belong to the same individual (as the MGL 615 M2). It is trapezoidal but narrower than the other teeth. As it is worn, the connections between the different structures and the extra-ridges are hardly visible. However, it appears that the parastyle turns to fuse with the buccomesial border of the paracone, and the anteroloph is thickened at its junction with the preprotocrista. The postparacrista is scarved by a short buccal notch; it is separated from the parastyle by a slot and the unique mesostyle is prolonged in a short mesoloph as for the other teeth. The paraconule is protruding and the protoloph is connected to the preprotocrista. Preand post-protocristae are less diverging than on the other teeth. One can distinguish a metaconule similar in size to the paraconule. The metaconule is included within the metaloph, which is connected both to the posprotocrista and to a not well-defined endoloph-hypocone.
M2. Six molars were previously identified as M2, one being strongly digested. Our description is therefore based on five M2. All bear a protocone that is situated more lingual than the hypocone. Similarly, the metacone is placed slighly lingual to the paracone, but always more than on M1. Therefore, the mesial width is larger than the distal one.

Five (MGL 602, 606, 615, 618 and 622) have a similar shape, bearing a straight anteroloph leaving the anteroflexus open buccally. On MGL 623, the anteroloph is somewhat digested mesiobuccally and buccally, it turns to fuse with the buccomesial corner of the paracone. The preprotocrista is long and thick, and the postprotocrista and endoloph are shorter than on M1. The hypocone is only slighly larger than the anterostyle, and swollen at the end of the preprotocrista, as seen on the unworn MGL 602. The protoloph is straight until the paraconule, then oblique to the middle of the protocone (MGL 602, 606, 622 and 623), or more mesial on the preprotocrista. The paraconule is often smaller than the main metaconule, sometimes only slighly protruding (MGL 618 and 622). On the heavily worn MGL 615, its most worn area (dentine released by wear at the level of the paraconule) appears larger than the metaconule area. The postparacrista joins the mesostyle (except on MGL 615). The latter can bear one (MGL 602, 622, 623 and 633) or two (MGL 606 and 618) short mesolophs. The premetacrista can be absent (? MGL 615), short (MGL 618, 622 and 623), moderate (MGL 602) or long (MGL 606). MGL 606 displays the most lingual metacone and then the shorter posteroloph. On MGL 622, the metacone is displaced lingually and surrounded buccodistally by the posteroloph. The metaloph is lingually isolated from the lingual cusps on the main part of its height. However, there are very low connections from the postprotocrista, the endoloph or/and the hypocone to the base of the metaconule (MGL 602, 615 and 623). The bulged metaconule is single (MGL 606, 615 and 618) or doubled buccally (MGL 602, 622 and 623). There are four distomesial extra-ridges (two descending from the mesial flank of the metaloph, one from each metaconule to the mesoflexus (MGL 602 and 623); there are three mesiodistal extra-ridges from the protoloph distal flank and one from the paraconule (MGL 602 and 622). On MGL 606, two extra-ridges descend from the distal flank of the protoloph, one from the paraconule and one from the metacone-buccal metaloph, and two from the unique metaconule. The mesial flank of the paraconule displays weak undulations on MGL 623 to weak extra-ridges on MGL 606.

M3. Nine molars were identified as M3; two are badly damaged and their structures hidden (MGL 631 and 638), the mesial border of MGL 621 is broken, and MGL 234 is strongly worn. The anterostyle is present at the preprotocrista/anteroloph junction. The parastyle is faintly swollen; it is separated buccally from the paracone. The latter is the highest cusp, prolonged by a strong postparacrista, which joins a unique (MGL 613), double (MGL 621 and 627) to tripled (MGL 611 and 614) mesostyle. One to three short mesolophs are present, the most distal reaching the metaconule on two teeth (MGL 611 and 613). Mesial and distal extra-ridges descend from the buccal protoloph. The paraconule displays also such ridges; the mesial one allows its connection with the anteroloph on MGL 611 and 627. There is a slot or a weak connection between the paraconule 

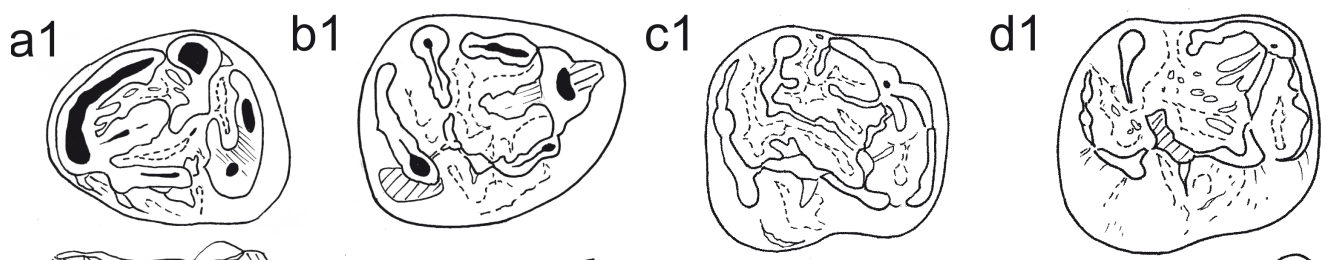

e1
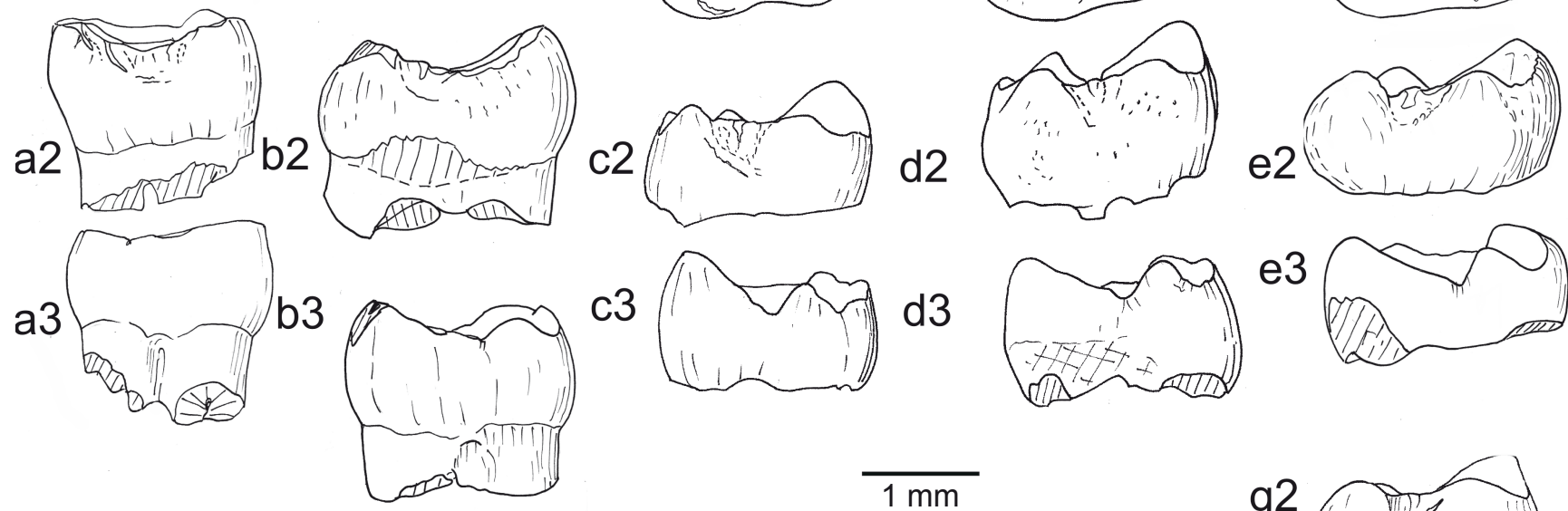

e3

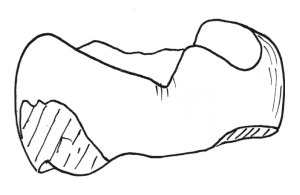

f1
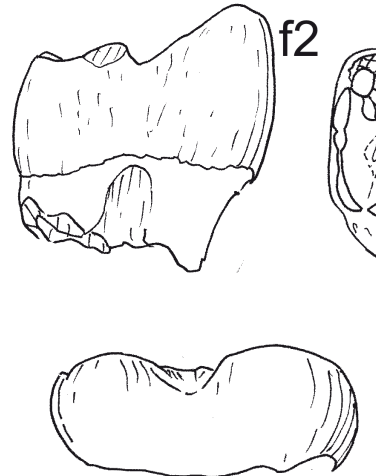

h2
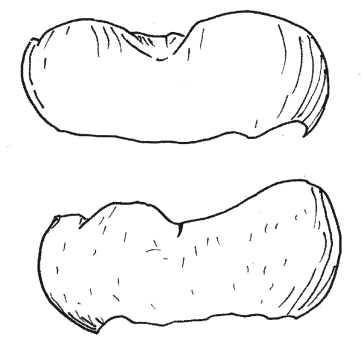
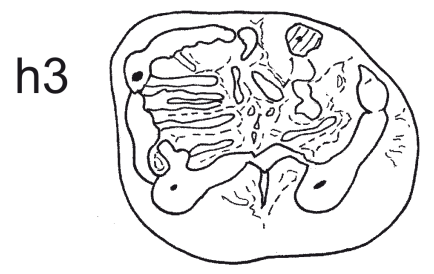

f3

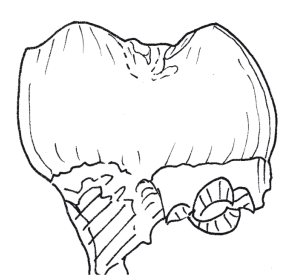

$1 \mathrm{~mm}$
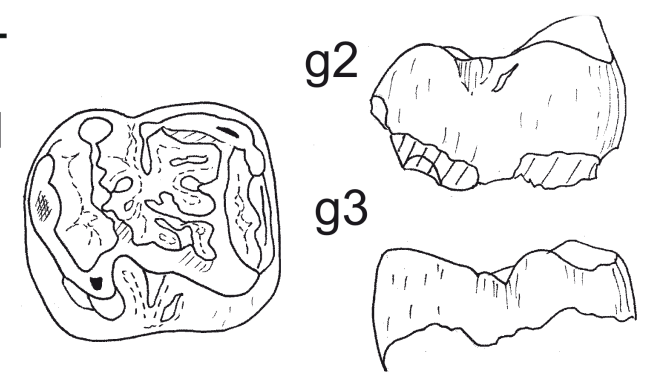

i1

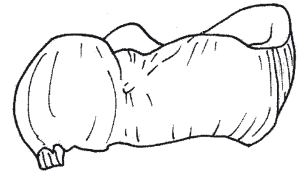

i3

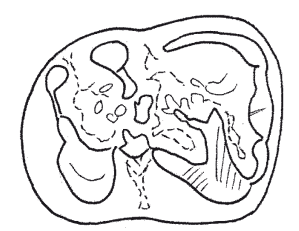

Text-fig. 11. Lower teeth of Masillamys mattaueri (HARTENBERGER) from Mas de Gimel (Hérault, France; MP 10, late early Eocene). a) MGL 641, left p4; a1 - occlusal view, a2 - buccal aspect, a3 - lingual aspect. b) MGL 220, right p4; b1 - occlusal view, b2 - buccal aspect, b3 - lingual aspect. c) MGL 233, right m1; c1 - occlusal view, c2 - buccal aspect, c3 - lingual aspect. d) MGL 665, right m1; d1 - occlusal view, d2 - buccal aspect, d3 - lingual aspect. e) MGL 225, holotype, right m2; e1 - occlusal view, e2 - buccal aspect, e3 - lingual aspect. f) MGL 222, left $\mathrm{m} 1$; f1 - lingual aspect, f2 - occlusal view, f3 - buccal aspect. g) MGL 231, right $\mathrm{m} 2$; g1 - occlusal view, g2 - buccal aspect, g3 - lingual aspect. h) MGL 646, left m3; h1 - buccal aspect, h2 - lingual aspect, h3 - occlusal view. i) MGL 619, right m3; i1 - buccal aspect, i2 - lingual aspect, i3 - occlusal view. Scale bar 1 mm.

and the thick lingual protoloph, attached to the middle of the protocone or to its anterior arm. There is a long curved low cingulum from the most distal mesostyle to the hypocone; this cingulum being expanded posteriorly on all the M3 except on MGL 627 where it it less expanded posteriorly. The metacone can be double (MGL 614 and 621). The hypocone is particularly reduced, and the endoloph can be distinct. The sinus is weak or absent. The metaconule is slighly bulged (MGL 613, 621 and 627), or stretched and indistinct from the centripetal extra-ridges (MGL 611 and 614).

Lower teeth. See Text-fig. 11.

p4. Only two p4 are available. The posterior root is flattened posteriorly, and the two roots are fused at least at their upper part, below the crown. The metaconid area (metaconid + it arms + protocristid, until the gutter of the mesoflexid) relative to the posterior part of the tooth (from the bottom of the mesoflexid slot to the distal border, appears shorter than on Pantrogna. As a result, the postmetacristid is shorter. The metaconid is more median (entirely for MGL 641; less for MGL 220). One mesiodistal extra-ridge descends from the metaconid apex to the bottom of the mesoflexid. Lingually, the postmetacristid is higher, and stops at a narrow slot, which represents the lingual opening of the mesoflexid. Buccally, the protoconid is present but reduced, lower than the metaconid, and attached to it by a short metalophid; following the protoconid, the postprotocristid goes mesiodistally to the mesoconid. A very narrow slot marks the contact postprotocristid-mesoconid. There is no distinct mesolophid and only a short ectomesolophid. There is no strong cingulid on the buccal slope of the protocristid and sinusid: only two short sloping ridges on MGL 641, and wrinkles on MGL 220. The entolophid is made of two parts, aligned obliquely from 
the entoconid to the postmesoconid or to the prehypocristid. The lingual half is fused to a short extra-ridge, making a connection with the mesiodistal extra-ridge of the metaconid on MGL 641. It is free on the other teeth. As seen on MGL 220 (the less worn), the prehypocristid is thin, short and distinct from the low and interrupted distal ectolophid. The hypoconulid is subsumed within the posterolophid, marked only by a thickening. The posterolophid is well separated from the entoconid on MGL 220; it weakly connects to a short postentocristid on MGL 641. The buccal surface of enamel is wrinkled, mainly on the sinusid flanks.

m1-m2. Six teeth from Mas de Gimel are $\mathrm{m} 1$ of $M$. mattaueri, and seven are m2. MGL 219 previously considered as a $\mathrm{m} 2$ is identified here as a $\mathrm{m} 1$ of another species, probably belonging to the genus Pseudoparamys (Tab. 1). The shape and size differences between $\mathrm{m} 1$ and $\mathrm{m} 2$ are rather minimal. The $\mathrm{m} 1$ are only slighly narrower than the $\mathrm{m} 2$ (Text-fig. 9), and even two couples of $\mathrm{m} 1-\mathrm{m} 2$ are of same size (MGL 612 $\mathrm{m} 1$ and MGL $228 \mathrm{~m} 2$; MGL $226 \mathrm{~m} 1$ and MGL $225 \mathrm{~m} 2$ ). On $\mathrm{m} 1$, the metaconid is slighly higher than the entoconid, and occupies a slighly more buccal position; but this is not quite evident, due to various states of wear and preservation. The hypoconid is also slighly more buccal than the protoconid on $\mathrm{m} 1$, and at the same level on $\mathrm{m} 2$.

Lower molars have generally a mesial arm (premetacristid) plunging to the straight linguobuccal anterolophid, which ends at the mesial flank of the protoconid, thereby closing the anteroflexid buccally. There is neither an antesinusid nor a swollen anteroconid. The anterolophid is as high as the metalophulid I and posterior arm of the hypoconid, as seen on the type and on weakly worn teeth. When the teeth are not too much heavily worn, it is possible to see that the transverse buccal metalophulid I joins the lingual metalophulid I, as on the type. On MGL 226, another linguobuccal ridge can be observed between the mesial premetacristid and the lingual metalophulid I. One to four mesiodistal low to very low extraridges descend from the lingual metalophulid I and from the buccal metalophulid I to the bottom of the talonid basin. The postmetacristid ridge descends moderately steeply to the mesoflexid lingual opening, which can be marked by a narrow and shallow slot. There is a swelling at the end of the postmetacristid (a kind of mesostylid), which can make a short flat on the lingual aspect; this flat being much less developed than in M. krugi. It is followed by a short lingual mesolophid on some teeth (MGL 226, 227, 231 and 233). The long oblique postprotocristid is strong, ending in a premesoconid swelling, weakly connected to the short mesial ectolophid. The weakly bulged mesoconid bears a more or less long ectomesolophid. Postprotocristid, mesial ectolophid and mesoconid are nearly aligned obliquely, whereas the distal ectolophid is offset lingually and joins the short prehypocristid. Buccally, the sinusid is wide and asymmetrical; its flanks bear extra-ridges and sometimes a sloping postprotoconid spur or prehypoconid spur. The mesoconid rarely bears a short mesolophid (MGL 222). Its distal extremity bears a short ridge linked to a strong postmesoconid swelling or ridge, which is separated (MGL $222,227,233$ and 665) or faintly connected to the lingual entolophid (all the other teeth), making a nearly continuous entolophid. The latter is however lower than the other transverse lophids. The short distal ectolophid is weaker than the mesial one, more often broken on weakly worn teeth.
The prehypocristid is short and weak. The posteroflexid is wide, due to the lack of connection of the entolophid with the hypoconid or with its prehypocristid. The posthypocristid is thick and high with respect to the hypoconulid. The latter is bulged and slighly higher than the posthypocristid. In the continuity, the short posterolophid is much lower, ending at the base of the entoconid, thereby living the posteroflexid open lingually. The enamel borders of the crown are rough and sometimes wrinkled. There are also some low granules and wrinkles in the flexids, more or less related to the main extra-ridges.

m3. Among the five teeth measured as $\mathrm{m} 3$ of $M$. mattauer $i$ from Mas de Gimel (Escarguel 1999: 330), only three are available, two are lacking (MGL 224 and 645). There are also one much worn (MGL 232) and one damaged (MGL 639) m3. Two relatively well-preserved (MGL 619 and 632) show few differences from the $\mathrm{m} 2$, out of the lower metaconid and the posterolophid shorter to absent. The buccal metalophulid is well developed and transverse as on $\mathrm{m} 1-\mathrm{m} 2$. The lingual metalophulid is less developed, reduced and never joining the buccal metalophulid, or replaced by mesiodistal extra-ridges. The postprotocristid + mesoconid + ectolophid are oblique. The extra-ridges are as on the other molars. The m3 MGL 646 is larger than the others, with a flatter crown, the entoconid more isolated and the hypoconulid doubled.

\section{General discussion and conclusion}

\section{Limbs}

The postcranial of $M$. mattaueri is not documented. Although a detailed analysis of the postcranial of Masillamys from Messel is beyond the scope of the present paper, preliminary observations, like the distinct body size and the divergent crural indexes, suggest that the two species $M$. beegeri and M. krugi differed in their locomotion.

\section{Skull features}

Contrary to previous interpretations, the two species of Masillamys (M. beegeri and M. krugi) share a wide i.o.f. They are both hystricomorphous. Moreover, as the dental evidence suggests that the species parvus belongs to the genus Masillamys, and their sister group being the hystricomorphous Pantrogna marandati + Hartenbergeromys hautefeuillei, it is expected that $M$. parvus was also hystricomorphous. This character is one of the synapomorphies of the Theridomorpha.

\section{Dental features}

Several dental features of Masillamys represent also synapomorphies of the Theridomorpha (Vianey-Liaud and Marivaux 2017). These are notably: the presence of a well-developed hypocone on upper teeth, the unilateral hypsodonty - even if weak -, the occurrence of a mesostyle and buccal mesoloph, the thick protoloph and metaloph (at least in their buccal part). On the lower teeth, these would be mainly the strong development of the oblique buccomesial to linguodistal postprotocristid, the short ectolophid, the continuous entolophid, the metalophulid I attached 
buccally to the apex of the protoconid, and the absence of a metalophulid II.

Regardless of the shared primitive features, like for instance the metaconid being the highest cuspid on lower teeth, the hypocone being smaller than the protocone on upper molars, the occurrence of a hypoconulid, para- and metaconule, or the remaining DP3 and P3, some non-plesiomorphic dental features seem to characterize basal theridomorphs. For instance, they are the mesiodistal (and/or distomesial) extraridges along the buccal protoloph and metaloph on upper teeth, as well as along the metalophulid I and entolophid on lower teeth. There are also a few smaller wrinkles or granules within the flexi(id)s along the anteroloph(id) and posteroloph(id), and within the mesoflexi(ids). On lower molars, the anteroconid is not markedly swollen; it is aligned with a plunging mesial arm of the metaconid (= linguobuccal mesial premetacristid). Finally, on upper teeth, anterostyle and posterostyle are often present.

\section{Conclusion}

The present work had for prime objective to clarify the identification of the species previously referred to the genus Masillamys from Messel, and more specifically to revise their diagnosis and differential dental features, as well as their infraorbital foramen conditions. On the basis of observations of their reconsidered infraorbitary area and on their dental features, the species of Masillamys will be included in a wider phylogenetic study dealing with lower and middle Eocene European rodents (Vianey-Liaud and Marivaux, work in progress). This study should enable to specify the first stages of the adaptive radiation of theridomorphs, which appear earlier than previously considered (Vianey-Liaud and Marivaux 2017). Furthermore, building on the present systematics work, these remarkable fossils, often preserved as compressed skeletons, can be further investigated using microCT scan methods and 3D reconstructions, in order to provide 3D digital models of long, carpal and tarsal bones, and then to investigate their locomotion and other aspects of their palaeoecology.

\section{Acknowlegdments}

This work has benefited from the collections and facilities of the Senckenberg Research Institute and Natural History Museum Frankfurt and the Hessische Landesmuseum in Darmstadt, for the material from Messel, and from the ISE-M (Université de Montpellier) for the other localities mentioned. Thanks to the Senckenberg Research Institute and Natural History Museum team in Frankfurt and to Torsten Wappler in Darmstadt for their efficient and warm welcome. This is ISE-M publication $n^{\circ} 2019-215$.

\section{References}

Emry, R. J., Thorington, R. W. (1983): Descriptive and comparative osteology of the oldest fossil squirrel, Protosciurus (Rodentia, Sciuridae). - Smithsonian Contributions to Paleontology, 47: 1-35.

https://doi.org/10.5479/si.00810266.47.1
Emry, R. J., Korth, W. (2007): A new genus of squirrel (Rodentia, Sciuridae) from the mid-cenozoic of North. Journal of Vertebrate Paleontology, 27: 693-698. https://doi.org/10.1671/0272-4634(2007)27[693:ANGOSR]2.0.CO;2

Escarguel, G. (1999): Les rongeurs de l'Eocène inférieur et moyen d'Europe Occidentale. Systématique, phylogénie, biochronologie et paléobiogéographie des niveaux-repères MP7 à MP14. - Palaeovertebrata, 28: 89-351.

Hartenberger, J.-L. (1968): Les Pseudosciuridae (Rodentia) de l'Eocène moyen et le genre Masillamys ToBiEN. - Comptes rendus de l'Académie des Sciences, sér. D, 267: $1817-1820$.

Hartenberger, J.-L. (1969): Les Pseudosciuridae (Mammalia, Rodentia) de l'Eocène moyen de Bouxwiller, Egerkingen et Lissieu. - Palaeovertebrata, 3(2): 27-61, 4 pls. https://doi.org/10.18563/pv.3.2.27-64

Hartenberger, J.-L. (1971): Contribution à l'étude des genres Gliravus et Microparamys (Rodentia) de l'Eocène d'Europe. - Palaeovertebrata, 4(4): 97-135, 5 pls. https://doi.org/10.18563/pv.4.4.97-135

Hartenberger, J.-L. (1975): Evolution des rongeurs primitifs de l'Ancien monde. - In: Problèmes actuels de paléontologie (Evolution des vertébrés). Colloque international du Centre national de la recherche scientifique, 218: 777-791, 1 pl.

Hartenberger, J.-L. (1990): L'origine des Theridomyoidea (Mammalia, Rodentia): données nouvelles et hypothèses. - Comptes rendus de l'Académie des Sciences, sér. 2, 311: 1017-1023.

Hartenberger, J.-L. (1993): New Rodents from the middle Eocene of Europe and Remarks about the Early History of the Group. - Kaupia, 3: 165-171.

Koenigswald, W. v., Storch, G., Richter, G. (1992): Rodents: At the start of a great career. - In: Schaal, S., Ziegler, W. (eds), Messel: An Insight into the History of Life and of the Earth. Oxford University Press, Oxford, pp. 217-222.

Lavocat, R. (1955): Quelques progrès récents dans la connaissance des rongeurs fossiles et leurs conséquences sur divers problèmes de systématique, de peuplement et d'évolution. - Colloque international du Centre national de la recherche scientifique, 60: 77-85.

Legendre, S., Marandat, B., Sigé, B., Crochet, J.-Y., Godinot, M., Hartenberger, J.-L., Sudre, J., Vianey-Liaud, M., Muratet, B., Astruc, J.-G. (1992): La faune de mammifères de Vielase (phosphorites du Quercy, Sud de la France): Preuve paléontologique d'une karstification du Quercy dès l'Eocène inférieur. - Neues Jahrbuch für Geologie und Paläontologie, Abhandlungen, 7: 414-428.

Lenz, O. K., Wilde, V., Mertz, D. F., Riegel, W. (2015): New palynology-based astronomical and revised ${ }^{40} \mathrm{Ar} /{ }^{39} \mathrm{Ar}$ ages for the Eocene maar lake of Messel (Germany). - International Journal of Earth Sciences, 104(3): 873-889. https://doi.org/10.1007/s00531-014-1126-2

Maier, W., Schrenk, P. (1987): The hystricomorphy of the Bathyergidae, as determined from ontogenetic evidence. - Zeitschrift für Säugetierkunde, 52(3): 156-164.

Michaux, J. (1968): Les Paramyidae (Rodentia) de l'Eocène inférieur du Bassin de Paris. - Palaeovertebrata, 1(4): 135-193, 10 pls. https://doi.org/10.18563/pv.1.4.135-193 
Ruf, I., Lehmann, T. (2018): Rodents - Gnawing Their Way to Success. - In: Smith, K. T., Schaal, S. F. K., Habersetzer, J. (eds), Messel, An ancient Greenhouse Ecosystem. - Schweizerbart, Stuttgart, pp. 263-270.

Schaub, S. (1958): Simplicidentata (Rodentia). - In: Piveteau, J. (ed.), Traité de Paléontologie. Masson et Cie, Paris, pp. 659-818.

Stehlin, H. G, Schaub, S. (1951): Die Trigonodontie der simplicidentaten Nager. - Schweizerische Paläontologische Abhandlungen, 67: 1-385.

Tobien, H. (1954): Nagerreste aus dem Mitteleozän von Messel bei Darmstadt. - Notizblatt des Hessischen Landesamtes für Bodenforschung, 82: 13-29, 2 pls.

Thaler, L. (1966): Les rongeurs fossiles du Bas-Languedoc dans leurs rapports avec l'histoire des faunes et la strati- graphie du Tertiaire d'Europe. - Mémoires du Muséum national d'Histoire naturelle, sér. C, 15: 1-295.

Vianey-Liaud, M. (1974): Palaeosciurus goti nov. sp., écureuil terrestre de l'Oligocène moyen du Quercy. Données nouvelles sur l'apparition des Sciuridae en Europe. Annales de Paléontologie, 60: 103-122.

Vianey-Liaud, M., Marivaux, L. (2017): Autopsie d'une radiation adaptative: Phylogénie des Theridomorpha, rongeurs endémiques du Paléogène d'Europe - histoire, dynamique évolutive et intérêt biochronologique. Palaeovertebrata monograph, 40(3-e1): 1-68.

https://doi.org/10.18563/pv.40.3.e1 


\section{Explanations to the plates}

\section{PLATE 1}

Masillamys beegeri, from Messel, SMF-ME 11295

1. Plate B, skull, right side.

2. Plate A, skull, left side.

3. Plate A of a complete skeleton, left side.

Abbreviations: a.c. - coronoid process of the dentary, D dentary, $\mathrm{F}$ - frontal, $\mathrm{J}$ - jugal, $\mathrm{M}$ - maxillary, $\mathrm{N}$ - nasal, OC - occipital/postparieta, $\mathrm{Pa}$ - parietal, $\mathrm{PM}$ - premaxillary, SQ - squamosal. The mesial opening of the infra orbitary foramen is underlined by white dotted line

\section{PLATE 2}

Masillamys beegeri, from Messel, SMF-ME 1287A: plate with right side of a juvenile

1. Skull, mesial opening of the infra orbitary foramen underlined by white dotted line. TR, tympanic ring, others abbreviations like for Pl. 1.

2. Complete skeleton with indication of some long bones lengths.

\section{PLATE 3}

Masillamys krugi, from Messel

1. HLMD-Me 11015a, plate with left side of the skeleton; $\mathrm{a}$ - head enlarged, $\mathrm{b}$ - complete skeleton, with indication of some long bones lengths.

2. HLMD-Me $11015 \mathrm{~b}$, plate with right side of the skeleton; $a$ - head enlarged, $b$ - incomplete skeleton, with right arm and thoracic cage. 
PLATE 1
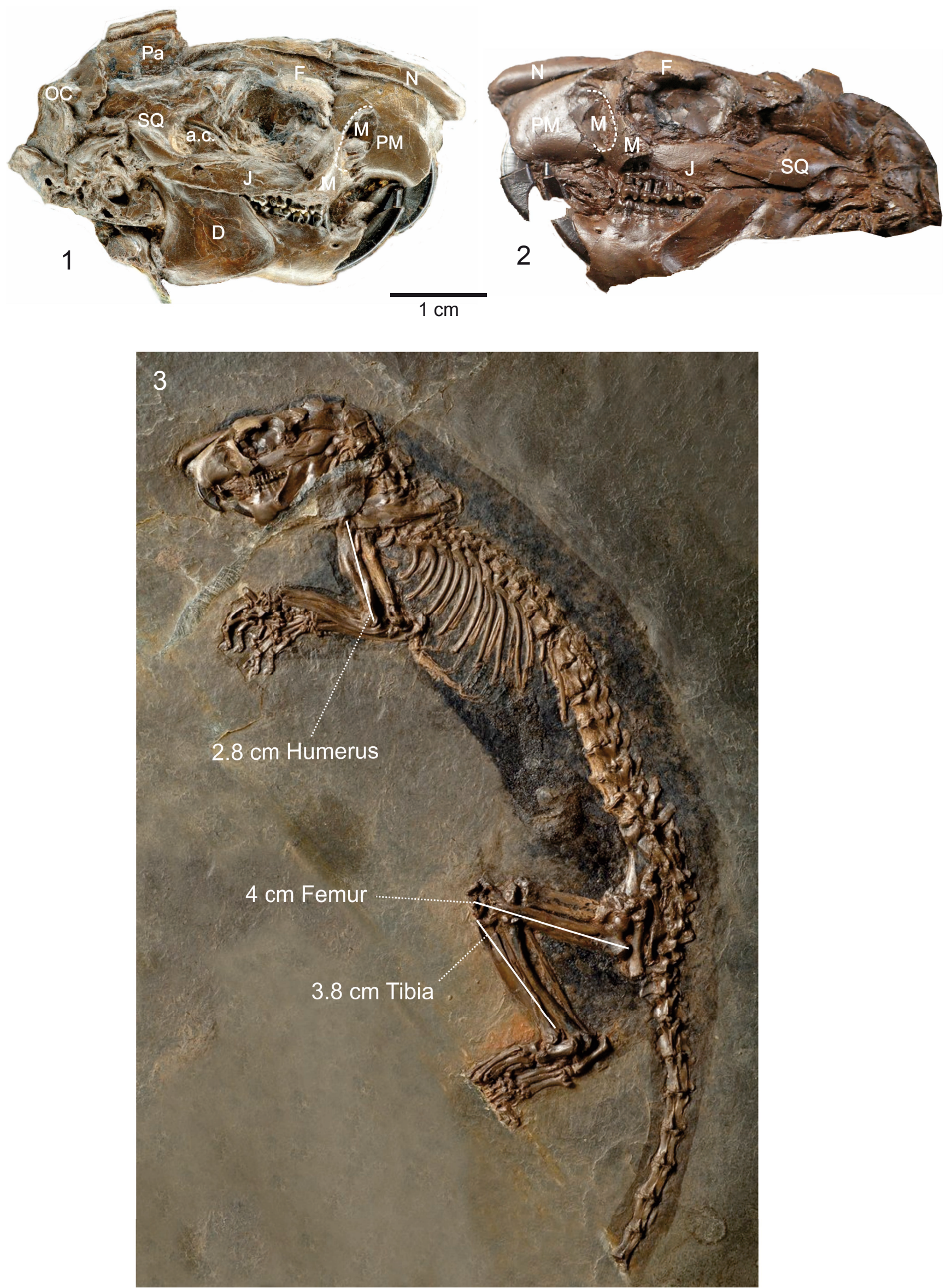
PLATE 2
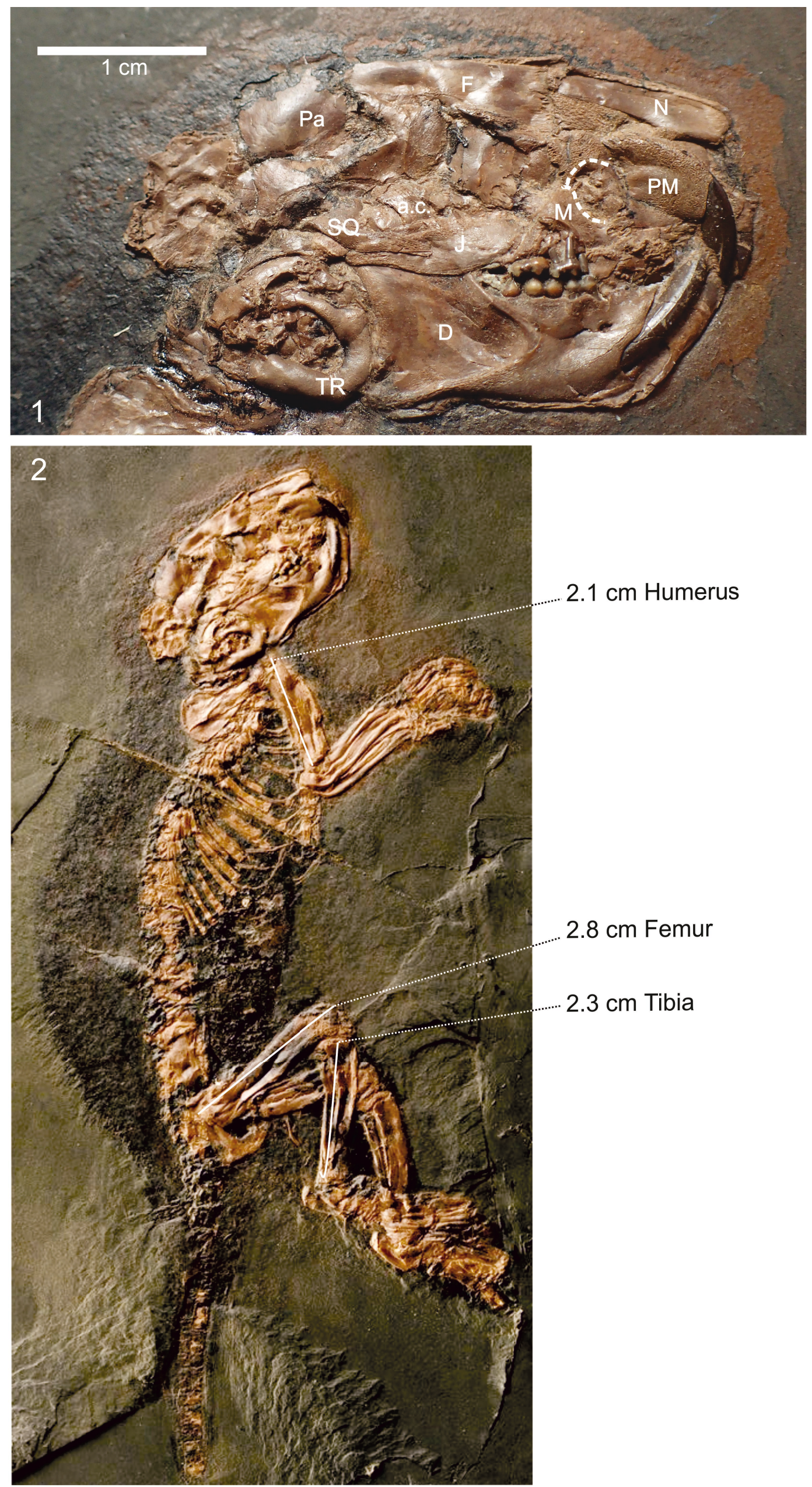

$2.1 \mathrm{~cm}$ Humerus

$2.8 \mathrm{~cm}$ Femur

$2.3 \mathrm{~cm}$ Tibia 


\section{PLATE 3}
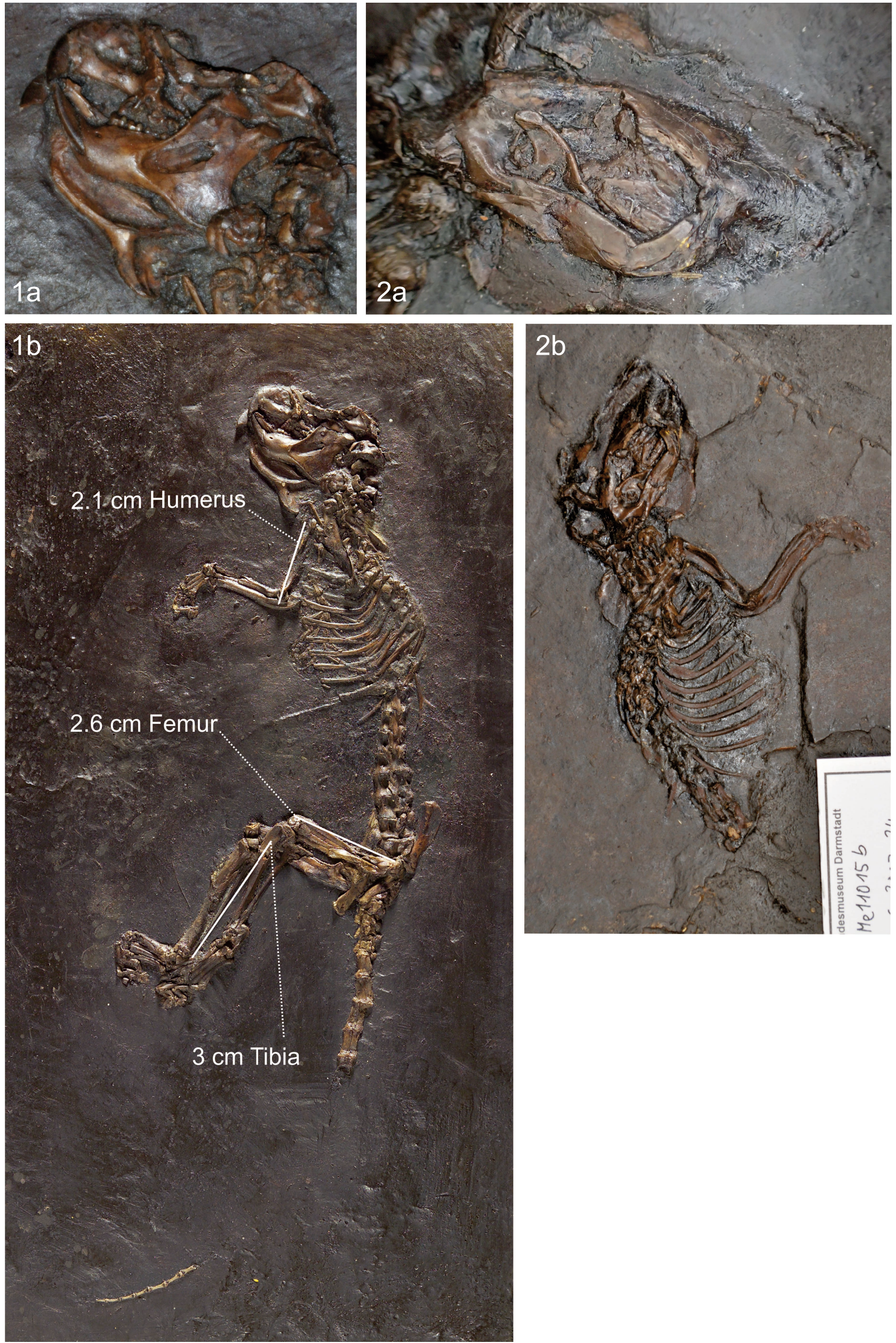